US Army Corps

of Engineers

Waterways Experiment

Station

Dredging Operations and Environmental Research Program

\title{
Improving Dredged Material Management Decisions with Uncertainty Analysis
}

by Donna J. Vorhees, Susan B. Kane Driscoll, Katherine von Stackelberg, Menzie-Cura and Associates, Inc.

Todd S. Bridges, WES 
The contents of this report are not to be used for advertising, publication, or promotional purposes. Citation of trade names does not constitute an official endorsement or approval of the use of such commercial products.

The findings of this report are not to be construed as an official Department of the Army position, unless so designated by other authorized documents. 


\section{Improving Dredged Material Management Decisions with Uncertainty Analysis}

by Donna J. Vorhees, Susan B. Kane Driscoll,

Katherine von Stackelberg

Menzie-Cura and Associates, Inc.

One Courthouse Lane, Suite Two

Chelmsford, MA 01824

Todd S. Bridges

U.S. Army Corps of Engineers

Waterways Experiment Station

3909 Halls Ferry Road

Vicksburg, MS 39180-6199

Final report

Approved for public release; distribution is unlimited

Prepared for U.S. Army Corps of Engineers

Washington, DC 20314-1000 


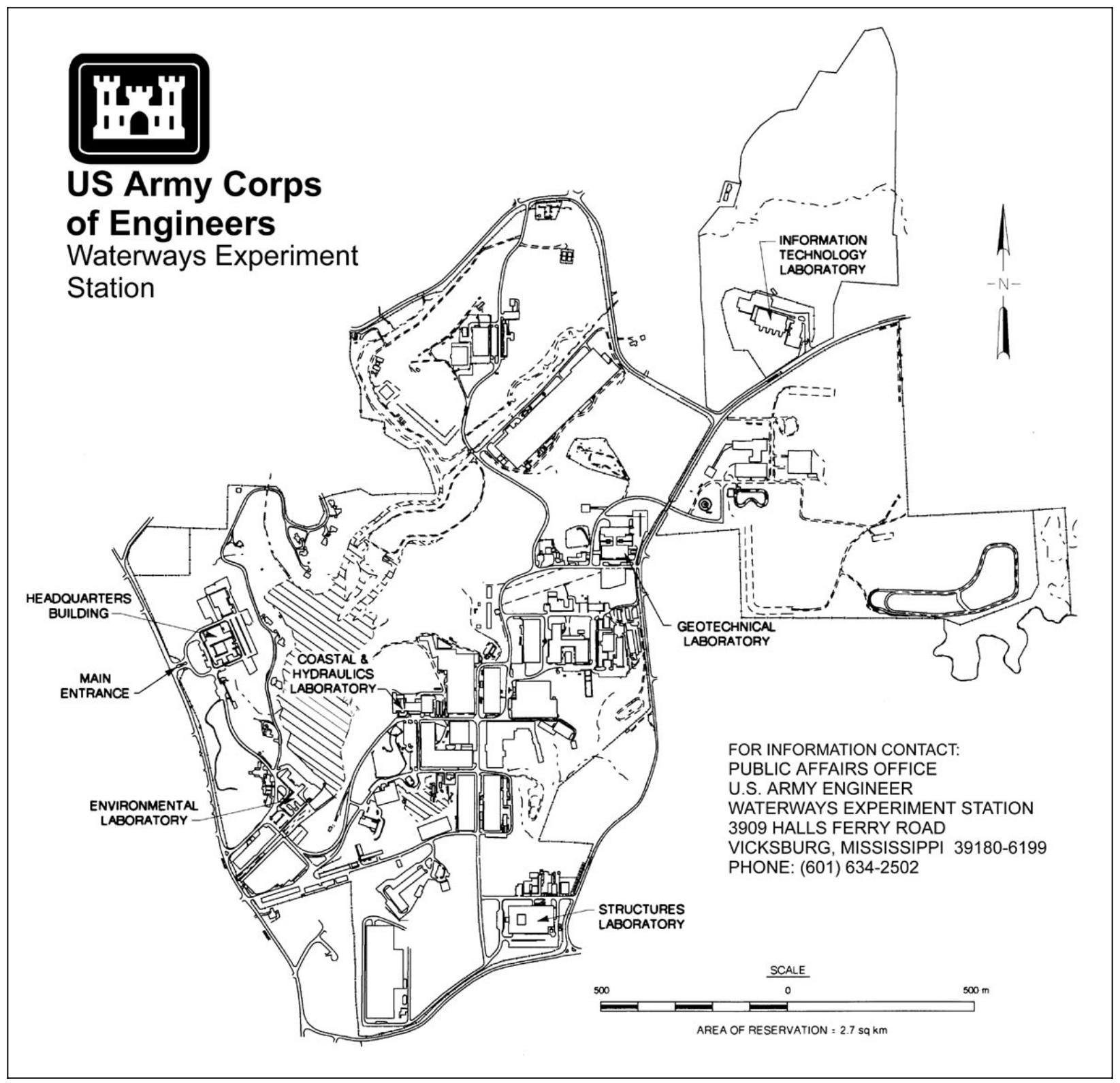

\section{Waterways Experiment Station Cataloging-in-Publication Data}

Improving dredged material management decisions with uncertainty analysis / by Donna J.

Vorhees ... [et al.] ; prepared for U.S. Army Corps of Engineers.

78 p. : ill. ; $28 \mathrm{~cm}$. -(Technical report ; DOER-3)

Includes bibliographic references.

1. Dredging - Management - Evaluation. 2. Contaminated sediments. 3. Risk assessment. I. Vorhees, Donna J. II. United States. Army. Corps of Engineers. III. U.S. Army Engineer Waterways Experiment Station. IV. Dredging Operations and Environmental Research Program (U.S.) V. Series: Technical report (U.S. Army Engineer Waterways Experiment Station) ; DOER-3.

TA7 W34 no.DOER-3 


\section{Dredging:}

Contaminated Sediments

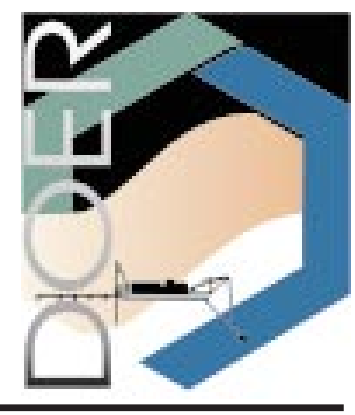

\section{Improving Dredged Material Management Decisions with Uncertainty Analysis (TR DOER-3)}

ISSUE: Federal laws and regulations require the U.S. Army Corps of Engineers (USACE) and U.S. Environmental Protection Agency (USEPA) to assess the potential for dredged material management activities to have significant undesirable effects on human health or the environment. The USACE and USEPA have developed an evaluation process for making dredged material management decisions to protect against such effects. Uncertainty regarding the ecological and human health risks associated with dredged material disposal alternatives can lead to delayed, costly, and unwise decisions. Uncertainty about the likelihood for unacceptable impacts can result from the lack of knowledge about critical elements or processes contributing to risk or natural variability in the same elements or processes.

RESEARCH: The objective was to discuss the importance of uncertainty in environmental decision making through specific reference to the dredging program. The approach taken included the following steps:

- Describing in detail the uncertainty sources within the tiered evaluation process.

- Ranking sources of uncertainty within the tiered evaluation process by degree of contribution.
- Making preliminary recommendations for further refinement of the ranking.

SUMMARY: The most significant sources of uncertainty within the tiered evaluation process included identification of the contaminants of concern, the selection and use of reference sediments, trophic transfer of sediment-associated contaminants, the potential for chronic toxicity and the use of chronic sublethal bioassays, definition of assessment and measurement end points during the conduct of an environmental risk assessment, the use of contaminant fate and transport models, tissue-based measures of toxicity, dose-response models for human receptors, and the toxicity of complex mixtures. Specific recommendations for the need for more extensive field validation for many of the components in the tiered evaluation process were made.

AVAILABILITY OF REPORT: The report is available in .pdf format on the World Wide Web at http://www.wes.army.mil/el/dots and through Interlibrary Loan Service from the U.S. Army Engineer Waterways Experiment Station (WES) Library, telephone (601) 634-2355. To purchase a copy of the report, call NTIS at (703) 487-4780.

About the Authors: Dr. Todd S. Bridges performs research at WES; contract support was provided by Drs. Donna J. Vorhees and Susan B. Kane Driscoll and Ms. Katherine von Stackelberg, Menzie-Cura and Associates, Inc., Chelmsford, MA. Point of Contact: Dr. Todd S. Bridges, Principal Investigator, telephone (601) 634-3626, or e-mail bridget@mail.wes.army.mil. 


\section{Contents}

Preface $\mathrm{V}$

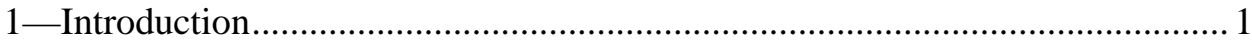

USACE/USEPA Technical Framework for Evaluating Environmental

Effects of Dredged Material Management Alternatives ................................ 1

General Description of Uncertainty Analysis............................................ 2

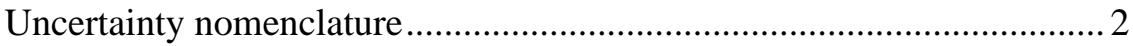

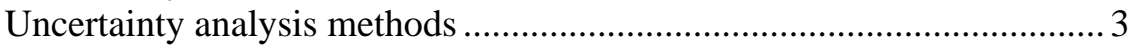

Improvement of Dredged Material Management Decisions by

Uncertainty Analysis .............................................................................. 4

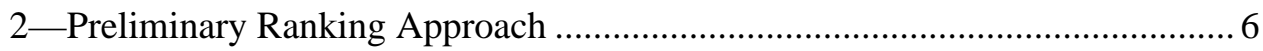

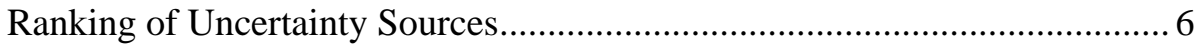

Criteria Used to Evaluate Importance of Uncertainty Sources..................... 10

Failure to consider potential adverse effect ........................................ 10

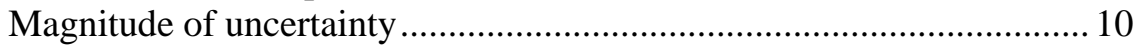

The ease with which the uncertainty can be quantified ........................... 11

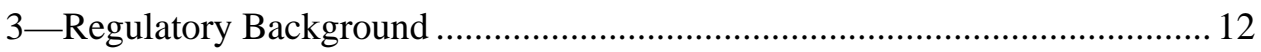

Technical Framework Summary ............................................................ 12

Regulatory Framework ....................................................................... 13

4-Uncertainty in Tiered Evaluation of Dredged Material ................................ 14

Tier I Evaluation..................................................................................... 15

Identification of contaminants of concern ........................................... 15

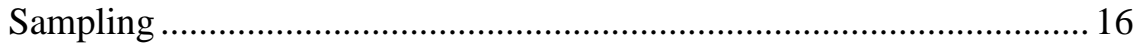

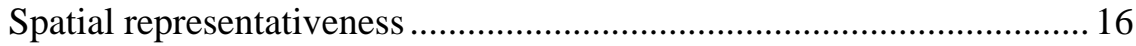

Analysis ....................................................................................... 17

Dredged material physical and chemical characteristics ........................ 17

Description of dredging and disposal activities ..................................... 17

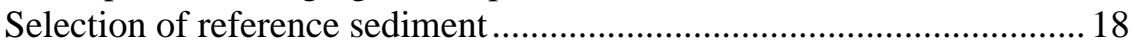

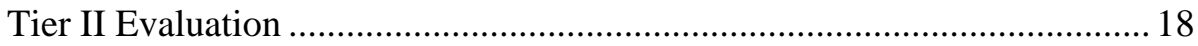

Water column impact-numerical mixing models.................................. 18

Benthic impact-Theoretical bioaccumulation potential for nonpolar

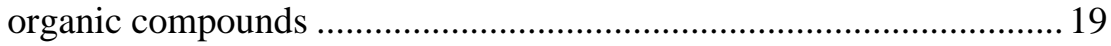


Equilibrium-partitioning sediment guidelines .................................... 21

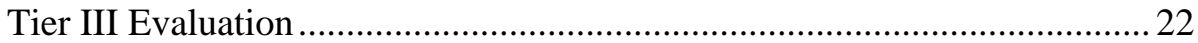

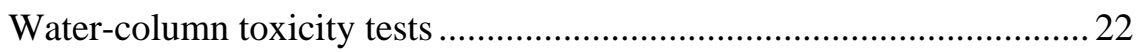

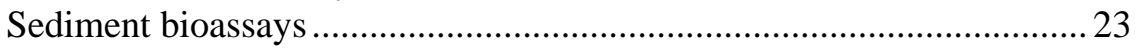

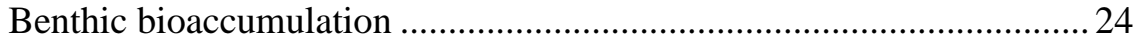

Tier IV Evaluation..................................................................... 27

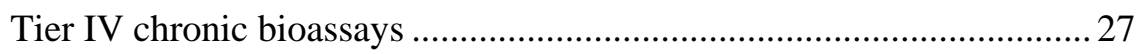

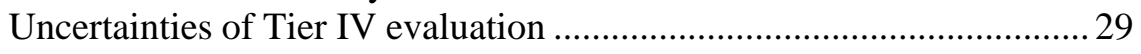

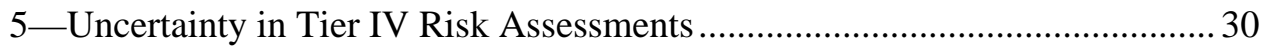

Problem Formulation/Hazard Identification.................................................30

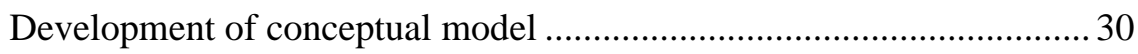

Assessment and measurement end points ............................................... 32

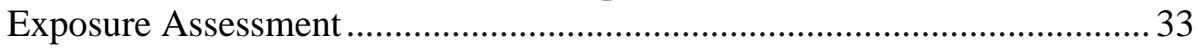

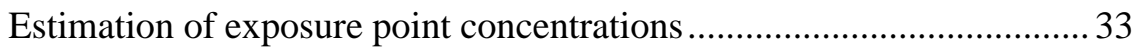

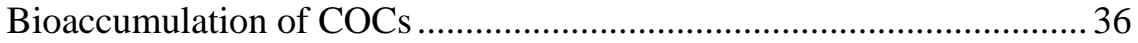

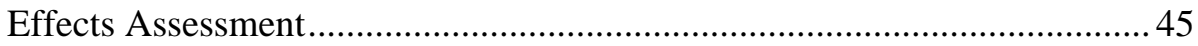

Toxicity end points for ecological receptors....................................... 45

Toxicity end points based on body burdens .............................................46

Human receptors: Dose-response models for carcinogens and

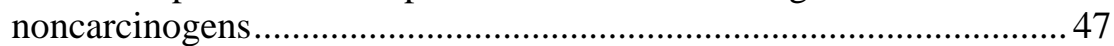

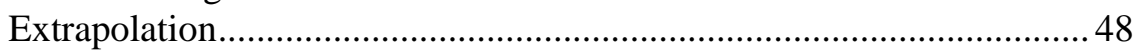

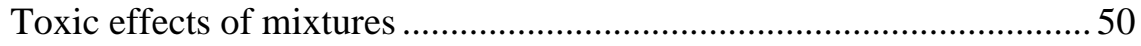

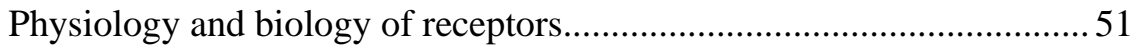

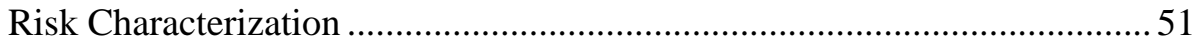

Estimation of population-level effects from effects on individuals ........52

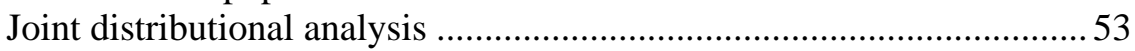

Temporal considerations: Potential for recovery of populations .............53

6-Preliminary Ranking and Recommendations............................................54

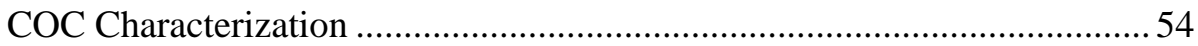

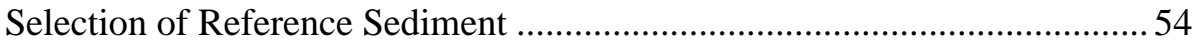

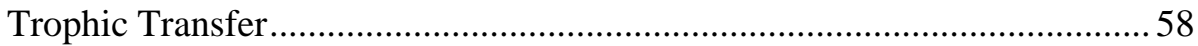

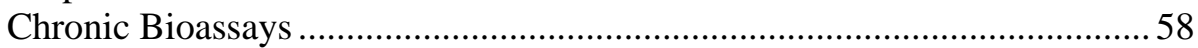

Assessment and Measurement End Points ...............................................58

Fate and Transport Models.....................................................................58

Toxicity End Points Based on Body Burdens for Ecological Receptors....... 59

Dose-Response Models for Human Receptors.............................................. 59

Toxicity of Complex Mixtures ....................................................................5 59

The Need for Field Validation............................................................... 60

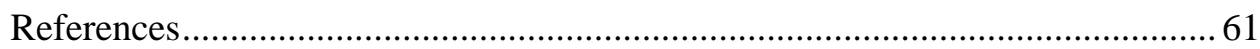

\section{SF 298}




\section{Preface}

The work described in this report was authorized by Headquarters, U.S. Army Corps of Engineers (HQUSACE), as part of the Dredging Operations and Environmental Research (DOER) program under Work Unit 33182, "Risk Characterization of Dredged Material," of the Risk Focus Area, managed by Dr. Todd S. Bridges, Environmental Laboratory (EL), U.S. Army Engineer Waterways Experiment Station (WES), Vicksburg, MS. DOER Program Managers are Dr. Robert M. Engler, EL, and Mr. E. Clark McNair, Coastal and Hydraulics Laboratory, WES. DOER Program Monitors are Messrs. Barry Holliday, Joseph Wilson, John Bianco, and Charles Chestnutt, HQUSACE.

The work was performed and the report written by Dr. Donna J. Vorhees, Dr. Susan B. Kane Driscoll, and Ms. Katherine von Stackelberg of Menzie-Cura and Associates, Inc., Chelmsford, MA; and Dr. Bridges.

At the time of publication of this report, Acting Director of WES was COL Robin R. Cababa, EN.

This report should be cited as follows:

Vorhees, D. J., Kane Driscoll, S. B., von Stackelberg, K., and Bridges, T. S. (1998). "Improving dredged material management decisions with uncertainty analysis," Technical Report DOER-3, U.S. Army Engineer Waterways Experiment Station, Vicksburg, MS.

The contents of this report are not to be used for advertising, publication, or promotional purposes. Citation of trade names does not constitute an official endorsement or approval of the use of such commercial products. 


\section{Introduction}

Uncertainty about ecological and human health risk associated with dredged material disposal alternatives can lead to delayed, costly, and unwise decisions. This report examines sources of uncertainty in evaluating impacts of open-water disposal with the goal of improving dredged material management decisions. Uncertainty sources are prioritized to focus U.S. Army Corps of Engineers (USACE) resources on reducing principal contributors to uncertainty and the controversy that often accompanies it.

This report begins with a brief description of the USACE tiered evaluation of dredged material, a summary of uncertainty analysis tools, and an explanation of how uncertainty analysis can improve USACE dredged material disposal decisions. Chapters 2 through 6 discuss the following:

a. The approach used to rank uncertainty sources in the tiered evaluation (including complete risk assessments) of dredged material disposal at open-water sites.

b. A detailed discussion of uncertainty sources within the tiered evaluation of dredged material disposal.

c. Results of the preliminary ranking and recommendations for further refinement of the ranking.

\section{USACE/USEPA Technical Framework for Evaluating Environmental Effects of Dredged Material Management Alternatives}

The U.S. Environmental Protection Agency (USEPA)/USACE Technical Framework (USEPA/USACE 1992) for evaluating environmental effects of dredged material management alternatives includes five major components: evaluation of dredging project requirements, identification of disposal alternatives, initial screening of alternatives, detailed assessment of alternatives, and alternative selection. This report focuses on a portion of this framework to identify important sources of uncertainty in evaluating dredged material for disposal in one type of alternative: an open-water site.

Prior to disposal, dredged material undergoes a four-tiered evaluation designed to match the level of analytical effort with the complexity of the 
decision to be made. Only a small fraction of dredged material disposal projects reach Tier IV. This evaluation addresses chemical impacts resulting from dredged material disposal. Physical impacts of disposal are not evaluated in this work because they are considered earlier in the site selection and designation process (USEPA/USACE 1992).

Tiers I, II, and III include elements of a complete ecological risk assessment. Tier I analysis demonstrates whether potential environmental impact can be determined based on existing information. Tier II provides rapid screening for potential impacts. Tier III includes toxicity and bioaccumulation testing of dredged material to determine whether it would be expected to cause unacceptable impacts. When Tier III analysis results in a highly uncertain conclusion, Tier IV may include a risk assessment.

A Tier IV risk assessment differs from analysis in earlier tiers by

a. Providing a comprehensive evaluation of human and ecological risk within a standard structure.

$b$. Explicitly identifying uncertainties in risk estimates.

The following sections analyze and rank sources of uncertainty in the context of this four-tiered evaluation. Future work will examine uncertainties associated with the assessment of potential environmental impacts of upland disposal alternatives and beneficial uses.

\section{General Description of Uncertainty Analysis}

Uncertainty analysis represents a collection of quantitative and qualitative methods that can be used to increase understanding of uncertainties in assessments of human health and ecological risk. Before describing how these methods might be applied to dredged material management, it is important to establish a vocabulary of uncertainty nomenclature.

\section{Uncertainty nomenclature}

In the environmental field, a nomenclature for uncertainty has evolved over the last decade (USEPA 1997b; Frey 1992). Uncertainty refers to a lack of knowledge, while variability refers to temporal-, spatial-, or population-level heterogeneity. This report uses the term uncertainty to describe uncertainty and the term variability where these sources have not been partitioned. In some instances, available data do not facilitate partitioning of uncertainty and variability.

Three principal types of uncertainty are recognized: scenario uncertainty, model uncertainty, and parameter uncertainty.

a. Scenario uncertainty originates from a lack of knowledge needed to specify a problem. For example, an exposure pathway that is important 
for human or ecological health might not be considered. Because scenario uncertainty is conceptual, it is difficult to quantify.

b. Model uncertainty arises from the necessary simplification of real-world relationships among environmental components. For example, bioaccumulation models are subject to imperfect knowledge about the potential for accumulation of contaminants by benthic invertebrates. This source of uncertainty is quantifiable, but the required level of effort necessary to describe the uncertainty could be substantial. It could be partially quantified by comparing model predictions with field measurements. In addition, results could be compared among models that have different structures, but are designed to predict the same output.

c. Parameter uncertainty arises from lack of knowledge about the true distribution of model parameters, perhaps due to measurement error. Measurement error is a common example of parameter uncertainty. This source of uncertainty can be measured in various ways. For example collection and analysis of field sample duplicates can provide an estimate of uncertainty that can be reduced by improving sampling and analytical methods. Of all the sources of uncertainty, parameter uncertainty is probably the easiest to quantify.

\section{Uncertainty analysis methods}

Uncertainty analysis methods range from qualitative approaches (e.g., expert judgment) to quantitative approaches, such as descriptive statistics and twodimensional Monte Carlo analysis. The choice among these methods depends on project objectives and the quantity and quality of available data. Several available methods are described as follows:

a. Descriptive statistics such as confidence intervals and standard deviation estimates can provide measures of uncertainty and variability.

b. Probabilistic analysis (with or without Latin Hypercube simulation) (Vose 1996; Burmaster and von Stackelberg 1991) is used to describe potential outcomes in terms of probability. With probabilistic approaches, one can calculate correlation between model input distributions and the predicted output distribution (e.g., exposure or risk) to identify inputs that strongly influence predictions. One probabilistic approach, two-dimensional Monte Carlo (Frey 1992; Burmaster and Wilson 1996), allows the conceptual differences between variability and uncertainty to be assessed separately. This separation facilitates the application of model results to policy questions about exposed populations and ecosystems, exposure levels, and research needs (Bogen and Spear 1987; Frey 1992).

c. Value of Information (VOI) (Thompson and Evans 1997) is a decision analytic framework that is an extension of uncertainty analysis. VOI is used to determine whether the cost of obtaining information prior to choosing a course of action is justified given the benefit of having that information as input to the decision. 
d. Interval Analysis, Fuzzy Arithmetic, or Dependency Bounds Analysis (Ferson and Burgman 1995; Ferson and Kuhn 1992). When insufficient information is available to conduct probabilistic analysis, these types of analysis might be appropriate. These methods explicitly acknowledge uncertainty but do not require the analyst to define distributions to input parameters.

e. Expert elicitation (Cooke 1991; National Council on Radiation Protection and Measurements (NCRP) 1996; Graham, Hawkins, and Roberts 1988; Evans et al. 1994) is also used in conjunction with these methods, where quantitative or qualitative information needed to assess risk is not available in the published literature.

f. Bayesian statistical procedures (Box and Tiao 1973; Gelman et al. 1995; Morgan and Henrion 1990) are based on the Bayesian, or subjective, view that probabilities can be estimated using scientific knowledge, expert judgment, experience, and intuition combined with new data.

The preliminary ranking of uncertainty sources in this report relies primarily on expert judgment. However, this ranking will be used to support recommendations for future, more detailed assessments of uncertainty in dredged material management. It is important to recognize that these methods can introduce new sources of uncertainty. For example, probabilistic analysis depends on the analyst identifying the appropriate shape of input distributions where there may be few data to support this selection.

\section{Improvement of Dredged Material Management Decisions by Uncertainty Analysis}

Evaluation of dredged material impacts on the environment depends on many input parameters and models that are subject to a great deal of uncertainty. How this uncertainty is treated quantitatively can lead to overestimates or underestimates of risk. The tiered approach for dredged material disposal decisions is designed to err on the side of conservatism to account for uncertainty. However, the approach does not explicitly address uncertainty quantitatively, resulting in predictions with unknown levels of conservatism built into them. The degree of conservatism varies from assessment to assessment, depending on the number of and mathematical relationship among input parameters (Ferson and Long 1995). Uncertainties must be acknowledged and quantified as much as possible to understand how confident one can be about a disposal decision.

Distinguishing sources of uncertainty and variability can improve predictions of potential adverse impacts. Uncertainty refers to a lack of knowledge, while variability refers to natural heterogeneity. Nature is replete with variability. The composition and abundance of populations can vary with climatic events or seasonal changes. Individuals within populations might vary in their response to chemical stressors in dredged material. For example, amphipods are often used as test species in whole-sediment bioassays, but a very different result might be 
obtained using another test taxon. Such variability can mask subtle adverse impacts in highly heterogeneous communities. To prevent this problem, uncertainty and variability should be partitioned analytically when making predictions of potential dredged material impacts. This partitioning allows the analyst to describe the effect of variability on a dredged material evaluation before deciding the importance of anthropogenic impacts. 


\section{Preliminary Ranking Approach}

\section{Ranking of Uncertainty Sources}

Uncertainty analysis is a critical step in improving dredged material decisions, although it is preceded by several important activities. First, data and information need to be collected, including historic data from the dredged material permitting program and information regarding parameter and model inputs required for estimating impacts. The quality of the collected data must be evaluated to determine whether the statistical distribution of input parameters can be described. In some cases, only a range (i.e., minimum and maximum values) of possible values will be available for use in a quantitative analysis of uncertainty.

The preliminary ranking of uncertainty sources described in this report does not ignore uncertainty sources that are hard to quantify, but it evaluates them only qualitatively. If available data do not support a distribution, or even a minimum and maximum value for a given input, one usually cannot quantify the contribution of the input to uncertainty in the assessment of possible impacts. For example, one cannot quantify the uncertainty associated with selecting a subset of sensitive receptors to represent a larger ecological community. Still, interpretation of predicted impacts and risks strongly depends (qualitatively, at least) on this selection, so it should not be ignored simply because one does not know how to quantify uncertainty.

To estimate the potential for environmental impacts associated with dredged material disposal, USACE uses scientific judgment and predictive models within the tiered evaluation procedure and, at times, within a full human health and ecological risk assessment. As the first step in ranking sources of uncertainty, data and information are gathered regarding these procedures. Relying on this information, major categories of uncertainty in the USACE tiered approach to dredged material evaluation are listed in Table 1. These categories are described as "aggregated" because they encompass more than one source of uncertainty. USEPA and others suggest that too much aggregation makes it difficult to evaluate and compare technical areas (Hattis and Goble 1994; Morgan 1994). For example, it might be important to separate "bioaccumulation of metals" from "bioaccumulation of nonpolar organic compounds" because there might be much greater uncertainty about bioaccumulation of metals. The aggregation in Table 1 is designed to simplify the ranking process without sacrificing important details. 


\begin{tabular}{|c|c|c|c|c|}
\hline \multicolumn{5}{|c|}{$\begin{array}{l}\text { Table } 1 \\
\text { Aggregated Sources of Uncertainty to be Evaluated for Their Relative Importance to Uncertainty in the Tiered Approach to } \\
\text { Dredged Material Decision Making }\end{array}$} \\
\hline Uncertainty Source & $\begin{array}{l}\text { Uncertainty } \\
\text { and/or } \\
\text { Variability }\end{array}$ & $\begin{array}{l}\text { Type of } \\
\text { Uncertainty }^{2}\end{array}$ & $\begin{array}{l}\text { Ease with Which } \\
\text { Uncertainty Can } \\
\text { Be Quantified? }\end{array}$ & $\begin{array}{l}\text { Magnitude of } \\
\text { Uncertainty }\end{array}$ \\
\hline \multicolumn{5}{|c|}{ Tier I Evaluation } \\
\hline $\begin{array}{l}\text { Identification of contaminants of concern (COCs) } \\
\text { Sampling uncertainty } \\
\text { Spatial representativeness }{ }^{5} \\
\text { Analytical uncertainty } \\
\text { Dredged material physical and chemical characteristics } \\
\text { Description of dredging and disposal activities including quantity of material to be dredged } \\
\text { Selection of reference sediment }\end{array}$ & $\begin{array}{l}u \\
u \\
u, v \\
u \\
u, v \\
u \\
u, v\end{array}$ & $\begin{array}{l}\text { Parameter } \\
\text { Parameter } \\
\text { Parameter } \\
\text { Parameter } \\
\text { Parameter } \\
\text { Scenario } \\
\text { Model }\end{array}$ & $\begin{array}{l}\text { Difficult } \\
\text { Easy } \\
\text { Easy } \\
\text { Easy } \\
\text { Easy } \\
\text { Easy } \\
\text { Difficult }\end{array}$ & $\begin{array}{l}\text { NR } \\
\text { Low } \\
\text { Low } \\
\text { Low } \\
\text { Low } \\
\text { Low } \\
\text { NR }\end{array}$ \\
\hline \multicolumn{5}{|c|}{ Tier II Evaluation } \\
\hline $\begin{array}{l}\text { Water Column Impact } \\
\text { Numerical mixing models } \\
\text { Benthic Impact } \\
\text { Theoretical bioaccumulation potential for nonpolar organics } \\
\text { Equilibrium sediment guidelines }\end{array}$ & $\begin{array}{l}u \\
u, v \\
u, v\end{array}$ & $\begin{array}{l}\text { Model } \\
\text { Model } \\
\text { Model }\end{array}$ & $\begin{array}{l}\text { Easy } \\
\text { Easy } \\
\text { Easy }\end{array}$ & $\begin{array}{l}\text { Moderate } \\
\text { Moderate } \\
\text { Moderate }\end{array}$ \\
\hline \multicolumn{5}{|c|}{ Tier III Evaluation } \\
\hline $\begin{array}{l}\text { Water Column Bioassay } \\
\text { Precision of bioassay } \\
\text { Interpretation of bioassay } \\
\text { Sediment Bioassay } \\
\text { Precision of bioassay } \\
\text { Interpretation of bioassay } \\
\text { Benthic Bioaccumulation } \\
\text { Bioavailability from sediment } \\
\text { Trophic transfer } \\
\text { Fish } \\
\text { Piscivorous birds } \\
\end{array}$ & $\begin{array}{l}u, v \\
u, v \\
u, v \\
u, v \\
u, v \\
u, v \\
u, v\end{array}$ & $\begin{array}{l}\text { Model } \\
\text { Model } \\
\text { Model } \\
\text { Model } \\
\text { Model } \\
\text { Model } \\
\text { Model }\end{array}$ & $\begin{array}{l}\text { Easy } \\
\text { Moderate } \\
\text { Easy } \\
\text { Easy } \\
\text { Easy } \\
\text { Easy } \\
\text { Moderate }\end{array}$ & $\begin{array}{l}\text { Low } \\
\text { Moderate } \\
\text { Low } \\
\text { Moderate } \\
\text { Moderate } \\
\text { High } \\
\text { High }\end{array}$ \\
\hline \multicolumn{5}{|c|}{$\begin{array}{l}\begin{array}{l}1 \\
2\end{array}=\text { uncertainty (lack of knowledge), and } v=\text { variability (population heterogeneity). } \\
{ }^{3} \text { See Chapter } 1 \text {, "Uncertainty nomenclature," for explanation of each category of uncertainty. } \\
\text { Uncertainty that is difficult to quantify may take the longest to assess. } \\
{ }^{4} \mathrm{NR}=\text { not ranked because insufficient data are available to estimate magnitude of uncertainty; Low = mathematical effect is an order of magnitude or less; Moderate = one or two } \\
\text { orders of magnitude; High = mathematical effect could be several orders of magnitude; PS = project-specific; MS = model-specific (magnitude of uncertainty can span the full range). } \\
{ }^{5} \text { Magnitude of uncertainty depends on sample size. }\end{array}$} \\
\hline & & & & (Sheet 1 of 3 ) \\
\hline
\end{tabular}




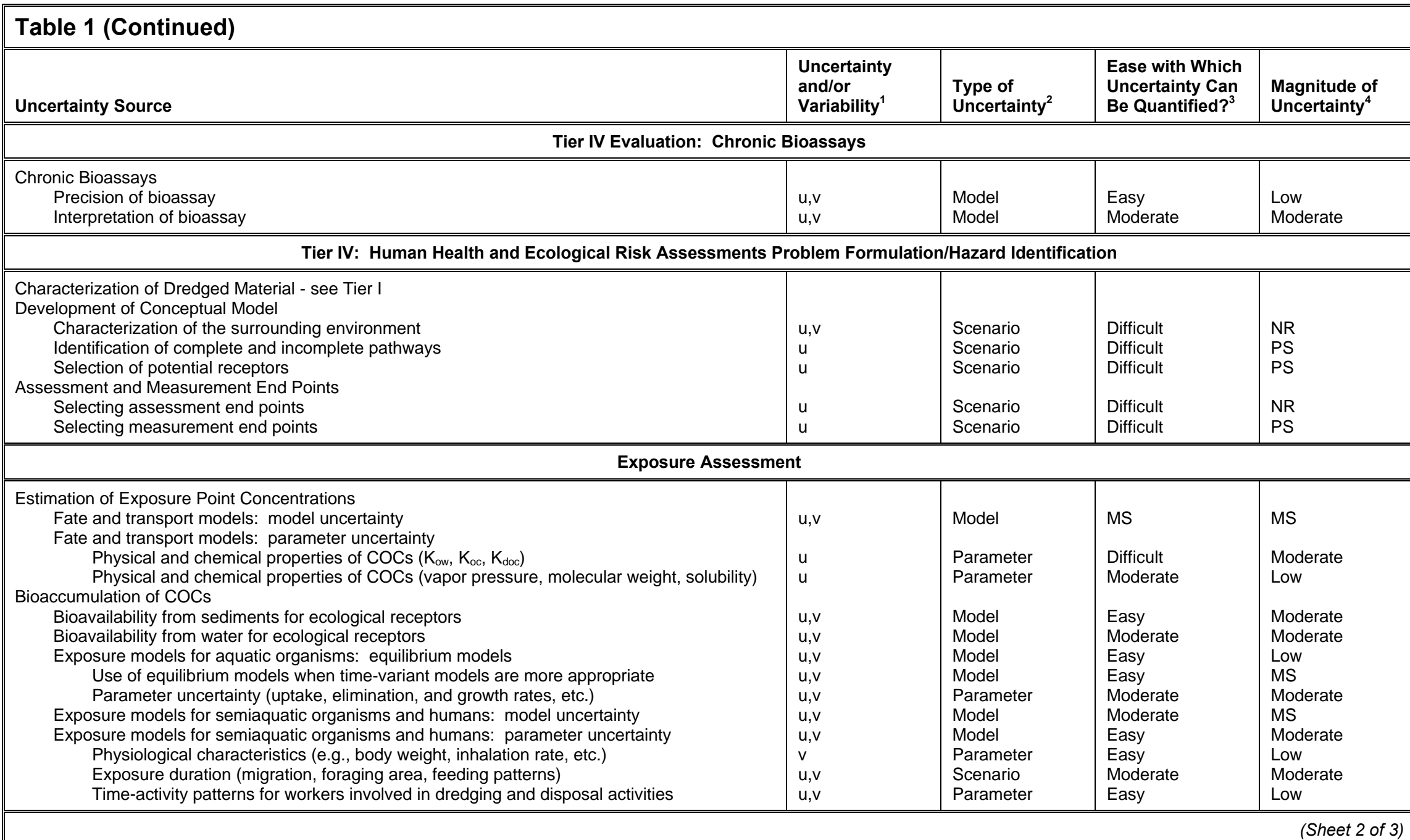




\begin{tabular}{|c|c|c|c|c|}
\hline \multicolumn{5}{|l|}{ Table 1 (Concluded) } \\
\hline Uncertainty Source & $\begin{array}{l}\text { Uncertainty } \\
\text { and/or } \\
\text { Variability }\end{array}$ & $\begin{array}{l}\text { Type of } \\
\text { Uncertainty }^{2}\end{array}$ & $\begin{array}{l}\text { Ease with Which } \\
\text { Uncertainty Can } \\
\text { Be Quantified? }^{3}\end{array}$ & $\begin{array}{l}\text { Magnitude of } \\
\text { Uncertainty }^{4}\end{array}$ \\
\hline \multicolumn{5}{|c|}{ Effects Assessment } \\
\hline $\begin{array}{l}\text { Toxicity end points for ecological receptors } \\
\text { Toxicity end points based on body burdens } \\
\text { Toxicity end points for human receptors } \\
\text { Dose-response models for carcinogens and noncarcinogens } \\
\text { Extrapolation } \\
\text { Intraindividual/intraspecies } \\
\text { Interspecies } \\
\text { Exposure period extrapolation } \\
\text { Lowest observed adverse effect level to no observed adverse effect level } \\
\text { Timing of exposure (e.g., exposure during sensitive life stages) } \\
\text { Toxicity of complex mixtures of COC (synergism, antagonism) }\end{array}$ & $\begin{array}{l}u, v \\
u, v \\
u, v \\
u, v \\
u, v \\
u, v \\
u \\
u, v\end{array}$ & $\begin{array}{l}\text { Model } \\
\text { Model } \\
\text { Parameter } \\
\text { Parameter } \\
\text { Parameter } \\
\text { Parameter } \\
\text { Model } \\
\text { Model }\end{array}$ & $\begin{array}{l}\text { Moderate } \\
\text { Moderate } \\
\text { Easy } \\
\text { Easy } \\
\text { Easy } \\
\text { Easy } \\
\text { Moderate } \\
\text { Moderate }\end{array}$ & $\begin{array}{l}\text { High } \\
\text { High } \\
\text { Low } \\
\text { Low } \\
\text { Moderate } \\
\text { Low } \\
\text { NR } \\
\text { High }\end{array}$ \\
\hline \multicolumn{5}{|c|}{ Risk Characterization } \\
\hline $\begin{array}{l}\text { Hazard/toxicity quotient approach } \\
\text { Potential recovery of populations } \\
\text { Estimation of population-level effects }\end{array}$ & $\begin{array}{l}u, v \\
u, v \\
u, v\end{array}$ & $\begin{array}{l}\text { Model } \\
\text { Model } \\
\text { Model }\end{array}$ & $\begin{array}{l}\text { Difficult } \\
\text { Difficult } \\
\text { Difficult }\end{array}$ & $\begin{array}{l}\text { NR } \\
\text { NR } \\
\text { Moderate }\end{array}$ \\
\hline
\end{tabular}


Table 1 indicates whether the source of uncertainty results from a lack of knowledge (uncertainty), population heterogeneity (variability), or both. Table 1 also identifies the general type of uncertainty: parameter, model, or scenario.

\section{Criteria Used to Evaluate Importance of Uncertainty Sources}

The importance of each uncertainty source in Table 1 to estimates of impact from dredged material management activities was evaluated using three criteria:

a. The uncertainty results from a failure to consider a potential adverse impact.

$b$. The magnitude of the uncertainty.

c. The ease with which the uncertainty can be reduced with available or readily obtained data and information.

Relevant scientific literature is reviewed in Chapters 3 through 5, and details of the USACE/USEPA tiered evaluation are compared against these criteria to evaluate uncertainty sources. The criteria are listed in order of importance, and uncertainty sources are scored accordingly as described in the following subsections. The data and information used to assign all scores are provided in the discussion of uncertainty sources in Chapters 4 and 5.

\section{Failure to consider potential adverse effect}

If a source of uncertainty exists because a potential adverse effect is not considered in the tiered evaluation (although it might be considered in a complete risk assessment conducted in Tier IV), the source was given a score of 3 .

Otherwise, no score was assigned to the source.

\section{Magnitude of uncertainty}

This criterion is used to indicate the degree of uncertainty associated with a particular source using quantitative data from the scientific literature. If no data were available to quantify uncertainty, the source was not ranked (NR) under this criterion. Some sources of uncertainty were classified as project-specific (PS) or model-specific (MS). None of these rankings received a score, but this does not necessarily mean the source of uncertainty is unimportant.

A ranking of "low" indicates uncertainty of up to one order of magnitude. A ranking of "moderate" indicates uncertainty of approximately one to two orders of magnitude, and a "high" ranking indicates uncertainty greater than two orders of magnitude. A low ranking received a score of 1, "moderate" received a score of 2, and "high" received a score of 3. NR, PS, and MS rankings did not receive a score. 


\section{The ease with which the uncertainty can be quantified}

Quantifying parameter uncertainty can be relatively simple with collection of appropriate data. Model uncertainty and scenario uncertainty are more difficult to quantify because they cannot be analyzed using straightforward statistical or mathematical techniques (Suter 1993). When uncertainty is not quantifiable (e.g., it cannot be described by a distribution or a range and there is no suitable analytical solution), then it becomes difficult to assess the magnitude of the effect. For example, choosing the contaminants of concern is partly restricted by what is possible to detect in the laboratory.

The ease with which uncertainty associated with different sources can be reduced was judged using the following criteria:

a. Is the uncertainty source categorized as parameter uncertainty?

b. Are data, models, or other types of quantitative information available to estimate uncertainty or can this information be obtained easily?

c. Is qualitative information available (e.g., expert opinion) to determine importance of uncertainty?

d. Have uncertainty analyses been performed?

For each source of uncertainty, a "yes" response to at least three of these questions resulted in a ranking of "easy." However, occasionally, these sources have been ranked "moderate" to account for limited validation of available models. A "yes" response to two of these questions resulted in a ranking of "moderate," and a "yes" response to none or one of these questions resulted in a ranking of "difficult."

This criterion was not used in the overall preliminary ranking; however, the results of this ranking will be useful in the future for planning efforts to reduce uncertainty. Overall preliminary scores can range from 1 to 6 . Chapter 6 summarizes results of the preliminary ranking of uncertainty sources. 


\section{Regulatory Background}

This chapter summarizes the technical framework and regulatory background, which define the open-water disposal option. As indicated in Chapter 1, this report focuses on uncertainty within that option only.

\section{Technical Framework Summary}

USACE has developed a technical framework to determine the environmental acceptability of various alternatives for disposing of dredged material (USEPA/USACE 1992). Possible alternatives include the following:

a. Open-water disposal is the placement of dredged material in rivers, lakes, estuaries, or oceans via pipeline or release from hopper dredges or barges. Such disposal may also involve appropriate management actions such as capping in a confined aqueous disposal (CAD) pit.

b. Confined disposal is placement of dredged material within diked nearshore or upland confined disposal facilities (CDFs) via pipeline or other means. The confinement dikes or structures in a CDF enclose the disposal area above any adjacent water surface, isolating the dredged material from adjacent waters during placement. CDFs may be constructed as upland sites, nearshore sites with one or more sides in water, or as island containment areas. If a hydraulic dredge is used to place material in the CDF, excess water is normally discharged from the $\mathrm{CDF}$ during filling operations. If CDFs are filled by mechanical rehandling of dredged material, less effluent is released.

c. Beneficial use includes a variety of options utilizing the material for some productive use. Examples of beneficial uses include beach nourishment, strip mine reclamation, shoreline stabilization, erosion control, and use in construction and industry.

The framework for selecting environmentally acceptable alternatives for the management of dredged material consists of the following five steps:

a. Evaluation of dredging project requirements.

b. Identification of alternatives.

c. Initial screening of alternatives. 
d. Detailed assessment of alternatives.

e. Alternative selection.

In the initial screening, alternatives may be eliminated from further consideration based on cost, technical feasibility, site availability, environmental impacts, or other factors. This report focuses on uncertainties associated with estimating potential environmental impacts due to chemical contamination of the dredged material for an open-water disposal alternative.

\section{Regulatory Framework}

Regulation of dredged material disposal is the shared responsibility of USACE and USEPA. USACE is the permitting authority while using environmental guidelines and criteria developed in conjunction and consultation with USEPA. Under the authority of the Marine Protection, Research and Sanctuaries Act (MPRSA) of 1972 and the Clean Water Act (CWA), these criteria and guidelines are used to evaluate the environmental acceptability of various management alternatives. These criteria and guidelines establish conditions under which the discharge of dredged material will not result in significant degradation of the aquatic ecosystem or unacceptable adverse environmental effects.

To determine environmental acceptability, the technical framework (USEPA/USACE 1992) outlines a detailed assessment of alternatives, which should include the following:

a. Evaluation of the adequacy and timeliness of existing data.

b. Evaluation of the physical characteristics of the sediment.

c. Initial evaluation of sediment contamination.

d. Performance of appropriate testing and assessments.

e. Evaluation of management options or control measures.

USEPA and USACE have established a tiered approach to testing and assessment of the potential environmental impacts of open-water dredging projects. These approaches are outlined in two documents, Evaluation of Dredged Material Proposed for Ocean Disposal - Testing Manual (USEPA/USACE 1991), otherwise known as the Ocean Testing Manual (OTM), and Evaluation of Dredged Material Proposed for Discharge in Waters of the U.S. - Testing Manual (USEPA/USACE 1998), referred to as the Inland Testing Manual (ITM). 


\section{Uncertainty in Tiered Evaluation of Dredged Material}

This section outlines important sources of uncertainty in the evaluation of potential environmental impacts of dredged material disposal. Uncertainty sources are discussed within the USACE/USEPA tiered evaluation structure (Figure 1).

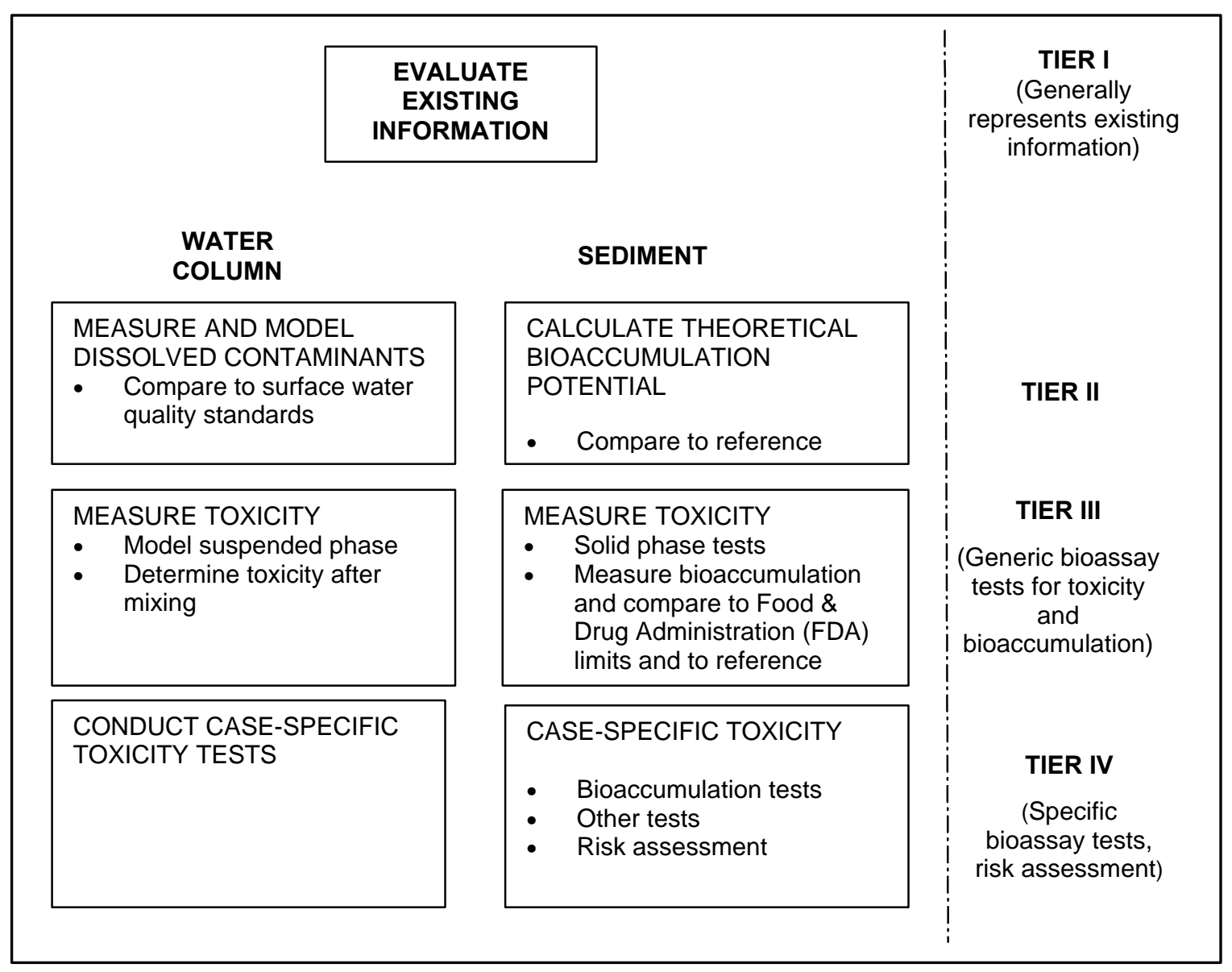

Figure 1. USACE/USEPA tiered evaluation of dredged material for disposal (after ITM (USEPA/USACE 1998)) 


\section{Tier I Evaluation}

The purpose of Tier I is to establish whether a determination of potential environmental impact can be made on the basis of existing information. All existing and readily available information on the proposed project, including previously collected chemical and biological monitoring and testing data, is evaluated. This information can be used to make a preliminary determination concerning the need for dredged material testing, under a principle commonly known as "reason to believe." The reason to believe that contaminants are not present and no testing is required is based on the type of material to be dredged (e.g., sand, silt, etc.) and its potential to be contaminated (e.g., due to proximity to sources of contamination). Contaminants of potential concern include those that might reasonably be expected to cause an unacceptable adverse impact if the dredged material is discharged.

\section{Identification of contaminants of concern}

The contaminants of concern (COCs) in the dredged material are selected based on the following criteria:

a. Presence in the dredged material.

$b$. Presence in the dredged material relative to the concentration in the reference sediment.

c. Toxicological importance.

d. Persistence in the environment.

e. Propensity to bioaccumulate from sediments.

Misapplication of selection criteria may result in the inappropriate inclusion or exclusion of chemicals as COCs. The following uncertainties are associated with the selection criteria:

a. Background comparison. Chemicals may be inappropriately retained or removed as COCs if background measures are not truly representative of background conditions.

b. Frequency of detection. Use of a high detection frequency (> 5 percent) as a selection criterion may result in the inappropriate exclusion of chemicals as COCs.

c. Essential nutrients/trace elements. Inclusion of essential nutrients or trace elements that are present naturally at beneficial concentrations or exclusion when present at toxic levels may result in inappropriate selection of COCs (U.S. Army Engineer Division, Huntsville, 1995).

The uncertainty associated with the selection criteria for identifying COCs is typically low and can be addressed by appropriate application of the criteria. Section 9 of the ITM (USEPA/USACE 1998) provides an extensive list of 
potential COCs that should be considered. However, it is possible that chronic toxicity could be related to unidentified compounds, such as endocrine disruptors. The uncertainty associated with COC selection is ranked NR, or not ranked, because data are not available to quantify the uncertainty associated with such omissions. Furthermore, without data, it would be difficult to quantify uncertainty.

\section{Sampling}

The primary sampling objective is to adequately characterize the concentration of contaminants in the dredged material and reference sediment. A number of quality assurance/quality control (QA/QC) techniques are used to assess the uncertainty associated with the sampling process. For example, blanks and duplicate samples are used to evaluate accuracy and precision, respectively.

It is important that sampling equipment and procedures satisfy all sampling objectives. For example, a dredge can fall toward the sediment at different speeds, resulting in varying levels of sediment compression. This effect can lead to nonreproducible contaminant concentration estimates. Assuming that careful development of sampling protocols prevents such error, uncertainty associated with sampling is easy to quantify with the use of typical QA/QC procedures. The magnitude of sampling error is typically less than one order of magnitude (Mudroch and Azcue 1995).

\section{Spatial representativeness}

The OTM (USEPA/USACE 1991) and the ITM (USEPA/USACE 1998) provide guidance on how to develop a sampling plan that will meet the objectives of an environmental assessment. Because the spatial distribution of contaminants at any site is uncertain, one objective is to sample the site sufficiently to characterize the variability in concentrations of contaminants at the site. The sampling plan must be designed to collect enough samples to ensure that hot spots of contamination are not overlooked and to support a robust statistical evaluation of the spatial distribution of contaminant concentration.

Composite sampling is sometimes performed and is useful for obtaining a better estimate of the central tendency of contaminant concentrations for less cost than the equivalent number of individual samples. However, compositing can result in underestimates of the tails of concentration distributions. As a result, this type of sampling can underestimate the importance of any hot spots of contamination. This potential drawback should be considered in determining the optimum sampling approach.

Typically, this source of uncertainty can be easily quantified by collecting more samples. If the sampling plan is correctly designed, this source of uncertainty should be low (Mudroch and Azcue 1995). 


\section{Analysis}

Thousands of commonly used chemicals may become contaminants in sediment, water, and biota (Maugh 1978). The following uncertainties are associated with chemical analysis and identification of these contaminants:

a. Measurement error.

b. Treatment of reported values below detection limits.

c. Inability to identify all contaminants in an environmental sample if problems with chemical or matrix interferences are encountered in the analysis. These interferences may cause difficulties in quantifying a low concentration of a chemical because of high concentrations of other chemicals or natural compounds in the sample. Inability to measure all compounds in a sample may result in excluding potentially significant contaminants from the analysis.

Laboratory methods follow analytical standards developed by regulatory agencies. The uncertainty associated with analytical error is typically less than 30 percent (Keith et al. 1983; USEPA 1992), corresponding to a magnitude ranking of "low." It is easy to quantify uncertainty associated with analytical error by using typical QA/QC procedures.

\section{Dredged material physical and chemical characteristics}

The physical and chemical characteristics of the dredged material, together with attributes of the disposal site, will dictate contaminant migration pathways in the environment. This information will be used quantitatively in later tiers of the assessment process. At this stage, the information is important for identifying potential areas of concern. For example, contaminants in dredged material with high organic carbon content are less likely to dissolve into the water column than contaminants in dredged material with little organic carbon.

Uncertainty in characterizing the physical and chemical attributes of dredged material is low and easily quantified (USEPA 1996a). Standard methods exist for obtaining data on grain size distribution, water content, Atterberg limits, organic content, specific gravity, and bulk chemical concentrations (USEPA/USACE 1998). Uncertainty is inherent in the sampling and analytical process, but these sources of uncertainty are well understood.

\section{Description of dredging and disposal activities}

Specific characteristics of the disposal management alternatives under consideration are an important component of characterizing dredged materials. Only by identifying specific removal, transport, pretreatment, treatment, disposal, and effluent treatment methods can the potential for contaminant loss from each of these processes be addressed. For example, hydraulic dredging will result in a different potential for contaminant loss than will mechanical dredging. In the description of dredging and disposal activities, it is important to identify the 
physical features of the proposed facility, including size (i.e., spatial extent of potential contamination), and any control measures that may be imposed.

Although failure to adequately describe proposed activities could result in flawed decision making, information on the activities should be easy to obtain. Uncertainty associated with description of the dredging and disposal activities should be low if the project is well defined.

\section{Selection of reference sediment}

Selection of an appropriate site for collection of the reference sediment is crucial because it impacts decisions throughout the tiered evaluation. It is especially important to ensure that natural variability in contaminant concentrations is considered in all comparisons of dredged material and reference sediment.

USACE guidance provides advice for selecting reference locations and collecting reference sediment. A great deal of professional judgment is required to implement this guidance. Therefore, this uncertainty source received a ranking of NR, because there are no quantitative data with which to estimate uncertainty associated with the judgment of USACE and USEPA staff. Consequently, it would be difficult to quantify this uncertainty.

\section{Tier II Evaluation}

The purpose of Tier II is to provide a reliable, rapid screen for potential impact and thereby eliminate the need for further testing. This tier uses a numerical mixing model to screen for compliance with State water quality standards (WQS) and a calculation of the theoretical bioaccumulation potential (TBP) to screen for potential benthic impact. In the future, it is anticipated that Equilibrium-Partitioning Sediment Guidelines (ESGs) will be available for screening the potential for those materials not likely to be toxic.

\section{Water column impact-Numerical mixing models}

This screening analysis assumes that all of the contaminants in the dredged material are released into the water column during the disposal operation. Numerical mixing models estimate the concentration of contaminants in waters of the mixing zone surrounding the disposal site. If concentrations of all COCs are below WQS and if no synergistic effects are suspected, the dredged material complies with the WQS. Under no circumstances can the disposal of the dredged material cause the applicable marine WQS to be exceeded outside the disposal site at any time or within the disposal site after the 4-hour mixing period.

Highly conservative estimates of environmental impact attained from this screening level calculation are uncertain because

a. Most of the contaminant usually remains within the dredged material that settles to the bottom. 
$b$. Contaminants that are released in the water can become associated with dissolved organic matter in the water column and become less bioavailable for accumulation by biota.

If the results of the screening level calculation exceed applicable WQS, the mixing model can be rerun using the results from a standard elutriate test.

Professional judgment can be used to provide estimates of the range of possible values for the mixing area. Uncertainty in the mixing model approach can be evaluated by changing specific parameters in the model and evaluating the impact on the results. Therefore, uncertainty in the ability of this screening-level approach to make conservative predictions of concentrations of COCs in water is assumed to be "easy" to quantify. The magnitude of uncertainty is ranked "moderate" because such simple mixing zone modeling techniques yield orderof-magnitude estimates (USEPA/USACE 1998). The accuracy of WQS values was not assessed in these rankings.

\section{Benthic impact-Theoretical bioaccumulation potential for nonpolar organic compounds}

The TBP is an approximation of the equilibrium concentration of nonpolar organic contaminants in tissues of benthic invertebrates if the dredged material were the only source of contaminant to the organism. In this tier, a comparison is made between TBP calculated for the nonpolar organic contaminant of concern in the dredged material and for the same contaminants in the reference sediment. If the TBP for the dredged material exceeds that of the reference sediment, further evaluation of bioaccumulation in Tiers III or IV is appropriate.

At present, the TBP can be calculated only for nonpolar organics, such as polychlorinated biphenyls (PCBs). At equilibrium, a nonpolar organic chemical would be expected to associate with organic matter in sediment and with lipids in tissue. Therefore, the potential bioaccumulation of nonpolar organic chemicals from dredged material can be estimated from the organic carbon content of the material, the lipid content of the organism, and the relative affinities of the chemical for each of these phases. Biota-sediment accumulation factors (BSAFs) are ratios that describe the relationship between the concentration of a nonpolar organic chemical in the lipid phase in tissue of a sediment-dwelling organism and the concentration in the sediment organic carbon phase to which the organism is exposed. BSAFs are defined as:

$$
B S A F=\left(C_{B} / f_{L}\right) /\left(C_{S} / f_{O C}\right)
$$

where

$$
\begin{aligned}
& C_{B}=\text { concentration of contaminant in biota, } \mathrm{mg} / \mathrm{kg} \text { wet weight } \\
& \mathrm{f}_{\mathrm{L}}=\text { the fraction lipid of the biota, } \mathrm{kg} \text { lipid/ } \mathrm{kg} \text { wet weight }
\end{aligned}
$$




$$
\begin{aligned}
\mathrm{C}_{\mathrm{S}}= & \text { the concentration of contaminant in sediment, } \mathrm{mg} / \mathrm{kg} \text { dry weight } \\
\mathrm{f}_{\mathrm{OC}}= & \text { the fraction organic carbon in sediment, } \mathrm{kg} \text { organic carbon } / \mathrm{kg} \\
& \text { dry weight }
\end{aligned}
$$

McFarland (1984) calculated an average equilibrium BSAF of 1.7 for a suite of compounds, indicating a slight enrichment of chemical in the lipid phase. Rubinstein et al. (1987) showed that a value of 4.0 is appropriate for calculating the bioaccumulation potential of field-collected samples. The ITM and OTM (USEPA/USACE 1991, 1998) calculate the TBP, the concentration of contaminant in biota in $\mathrm{mg} / \mathrm{kg}$ wet weight, as:

$$
T B P=4\left(\frac{C_{s}}{f_{o c}}\right) f_{L}
$$

The TBP calculation is used in Tier II as a coarse screen to predict the magnitude of bioaccumulation likely to be associated with nonpolar organic contaminants in the dredged material. As a follow-up to the conservative TBP screening approach, sediment bioaccumulation tests are used in Tier III to measure actual accumulation of contaminants from samples of dredged material (USEPA/USACE 1991). USACE developed a database from these sediment bioaccumulation tests and other sources that demonstrates the variability in reported BSAFs. The BSAF database is available through the Dredging Operations Technical Support (DOTS) Web page of the USACE Waterways Experiment Station (http://www.wes.army.mil/el/dots/).

The following uncertainties are associated with BSAFs used in the TBP calculation:

a. Measured BSAFs are often lower than the equilibrium-based estimates. Several factors can cause deviations from equilibrium conditions. First, sequestration of polycyclic aromatic hydrocarbons (PAHs) into soot particles may reduce partitioning into pore water and bioavailability to benthic invertebrates. Second, metabolism of organic compounds by the organisms usually increases the rate of elimination and decreases steadystate body burden of the compound. Third, in some cases, sufficient time may not have elapsed for exposed organisms to reach equilibrium with the sediments.

b. Variability across species, or true population heterogeneity, for reported values in the DOTS database can be significant. For example, BSAFs reported for chrysene in the DOTS database range from 0.02 to 0.61 . Other recent work reports a median BSAF for all PAHs of 0.032 (USEPA 1998b). Uncertainty is introduced by using a single calculated $\mathrm{BSAF}$ across a range of species and contaminants in estimating TBP.

Limited validation of the TBP model can be accomplished by comparing the results of Equation 2 with Tier III bioaccumulation tests (corrected for steadystate conditions, if necessary). Uncertainty in the factor of 1.7 can be evaluated 
by examining the standard error on the slope of the regression equation used to derive the factor. However, these sources of uncertainty are irrelevant when TBP results for dredged material are used only for comparison with the TBP estimated for the reference sediment. The same BSAF equation is used to estimate TBP for dredged material and sediment; therefore, this term, as well as the fraction of lipid in the benthic organism, cancels out.

If the TBP is used only to compare dredged material with reference sediment, there is little advantage to better specifying the factor of four. The fractions of organic carbon and contaminant concentrations in sediment represent the key parameters. Uncertainty in these parameters is easily quantified and may span one or two orders of magnitude given the small sample sizes typically used (ranking of "moderate").

The potential for trophic transfer and for biomagnification of COCs is not considered in this tier. The importance of evaluating potential trophic transfer and biomagnification is discussed in sections on Tiers III and IV evaluations.

\section{Equilibrium-partitioning sediment guidelines}

ESGs are numeric concentrations of nonpolar organic contaminants in sediment that can be used to screen sediments for the potential to cause adverse effects to benthic organisms (DiToro et al. 1991). ESGs have been established for a suite of chemicals, and USACE and USEPA plan to use them in the future as part of a Tier II evaluation.

The ESG approach assumes that an equilibrium exists between the chemical sorbed to sediment organic carbon and chemical that is freely dissolved in the pore water. Because the chemical activity of each phase is the same at equilibrium, the effective exposure concentration is the same regardless of exposure route (e.g., from sediment or pore water). Therefore, the equilibriumpartitioning approach predicts that toxic effects will be observed at concentrations of freely dissolved chemical in pore water that are equal to concentrations that produce toxic effects in water-only exposures.

Because assumptions of the ESG approach are only approximately true, prediction will be uncertain. For example, the distribution of the PAHs between sediment organic carbon and pore water may not reach equilibrium if these compounds are trapped within soot (McGroddy and Farrington 1995; Gustafsson et al. 1997). Furthermore, some benthic organisms (e.g., tube-dwelling animals) that are exposed predominantly to the overlying water, rather than the pore water, may experience less exposure than predicted (Kane Driscoll, Harkey, and Landrum 1997; Kane Driscoll, Schaffner, and Dickhut 1998).

The uncertainty associated with the use of ESGs to predict sediment toxicity has been examined extensively (Kane Driscoll, Harkey, and Landrum 1997; Ankley et al. 1994). Equilibrium-partitioning based predictions of sediment toxicity can differ from experimentally determined toxicity by more than a factor of ten (Hoke et al. 1995; Kane Driscoll, Schaffner, and Dickhut 1998). Therefore, the magnitude of the uncertainty associated with the use of ESGs is expected to be moderate. 


\section{Tier III Evaluation}

Tier III testing assesses the impact of contaminants in the dredged material on appropriately sensitive organisms to determine whether there is potential for the dredged material to result in an unacceptable impact. Assessment methods used in Tier III are water-column and whole-sediment toxicity tests and bioaccumulation tests.

\section{Water-column toxicity tests}

Water-column toxicity tests evaluate the impact of dredged material on the water column by exposing test organisms to an elutriate dilution series containing both dissolved and suspended components of the dredged material. Water column bioassays must be used when there are no applicable WQS for all contaminants of concern or when there is reason to suspect that contaminants may exhibit synergistic effects.

In this test, if survival of animals exposed to undiluted elutriate is significantly less than survival of animals exposed to the dilution water, the median lethal concentration $\left(\mathrm{LC}_{50}\right)$ or median concentration causing some adverse effect $\left(\mathrm{EC}_{50}\right)$ is calculated. The $\mathrm{LC}_{50}$ is the concentration lethal to 50 percent of the test organisms. The $\mathrm{EC}_{50}$ is the concentration causing some sublethal effect (e.g., deformity, immobility) in 50 percent of the test organisms. The $\mathrm{LC}_{50}$ or $\mathrm{EC}_{50}$ is compared to the modeled concentration of dredged material in waters outside the mixing zone of the disposal site (USEPA/USACE 1998). The maximum allowed concentration outside the mixing zone is 0.01 of the $\mathrm{LC}_{50}$ or $\mathrm{EC}_{50}$.

The following uncertainties are associated with the use of water-column bioassays:

a. The guidance notes that the factor of 0.01 is intended for acute mortality data (e.g., to relate acute to chronic toxicity) and not for more subtle effects described by an $\mathrm{EC}_{50}$ (e.g., deformities, reduced growth or reproduction) (USEPA/USACE 1998). This factor has not been validated, though it is likely to overestimate the potential for effects during short exposures.

b. Although the test guidance recommends that three species, representing different phyla (e.g., crustaceans, fish, etc.), be used in the bioassay, it is not certain if results obtained with test species will represent sensitivity of species in the field. It is difficult to interpret the results of the bioassay relative to field conditions.

c. This bioassay does not address trophic transfer of persistent bioaccumulative compounds of concern from water-column organisms to predators at higher trophic levels. However, the potential for bioaccumulation from water and trophic transfer to higher levels is likely to be insignificant due to short exposure periods in the field. 
d. Elutriate and suspended-solids tests may artificially alter the availability of contaminants. For example, clumps of sediment might break apart during the test that would have remained intact in the field, resulting in an overestimate of the potential for effects.

Precision of water column bioassay. Because it is easy to quantify uncertainty due to precision error (Ingersoll et al. 1997) and the utility and accuracy of the standard elutriate test have been extensively field verified (USEPA 1996a), the magnitude of uncertainty is likely to be low.

Interpretation of water column bioassay. The magnitude of uncertainty is ranked "moderate" with at least a factor of 10 due to the extrapolation from acute to chronic effects (Kenaga 1982). Further uncertainty is introduced due to possible aeration and disaggregation of dredged material during the test procedure. Given the way the assay is performed and interpreted, these sources of uncertainty are more likely to overestimate the potential for effects than underestimate them.

Extrapolation of bioassay results to species in the field and from acute to chronic exposures represents the primary quantifiable sources of uncertainty. Two kinds of models are typically used for effects extrapolation (Suter 1993): (a) additive and multiplicative factor models (i.e., applying uncertainty factors to test results), and (b) statistical models (typically linear regression). As in the case of the factor of 0.01 applied to the water column toxicity test results, the use of these factors implies a linear relationship between the independent and dependent variables. Consequently, statistical extrapolation models can also be used in place of uncertainty factors. These models typically assume that the toxicological parameter of interest is characterized by a probability density function, and that all future observations are drawn from this distribution. For example, this approach has been used to determine USEPA Water Quality Criteria. The approach assumes that interspecies sensitivity follows a logtriangular distribution and the lower 5 percent concentration is used as the concentration affecting the most "sensitive" species (i.e., protection of 95 percent of the species).

In order to assess causality, toxicity testing must be linked to other models or toxicity tests specifically designed to identify contaminants or classes of compounds responsible for observed toxicity (Ingersoll et al. 1997). The water column toxicity bioassay can be performed and interpreted without knowing which contaminants are causing the toxic effect. However, it is not possible to predict in advance of the test which sediments might fail.

\section{Sediment bioassays}

Whole-sediment bioassays are designed to determine whether the dredged material is likely to cause unacceptable adverse effects on benthic organisms. The limiting permissible concentration (LPC) is defined as "that concentration which will not cause unreasonable acute or chronic toxicity or sub-lethal adverse effects based on bioassay results" (40 CFR 227.27). Dredged material does not meet this condition in the commonly used acute toxicity test if bioassay mortality (a) is statistically greater than in the reference sediment and (b) exceeds mortality 
(or other appropriate end point) in the reference sediment by at least 10 percent (or a value that is in accordance with approved testing methods, e.g., 20 percent for amphipod bioassays for marine or estuarine disposal).

The following uncertainties are associated with whole-sediment bioassays:

a. In some cases, nontreatment factors, such as ammonia or food ration, may influence results of whole-sediment bioassays and result in overestimation or underestimation of risk (Bridges, Farrar, and Duke 1997; Moore et al. 1996).

b. Temporal changes in toxicity are not considered in interpretation of the results. For example, contaminant concentrations might decline following disposal, reducing sediment toxicity. However, this possibility is not considered in the interpretation of bioassay results.

c. It is not certain if results obtained with the test species will represent the sensitivity of species in the field.

d. Results of acute toxicity tests may not protect against adverse population-level effects.

$e$. They do not address adverse impacts resulting from biomagnification of dredged material contaminants.

Another source of uncertainty in interpreting bioassays relates to the use of statistical techniques to test the difference between reference sediments and site sediments, and undiluted and diluted elutriate. Thus, there is uncertainty in evaluating the probability that there is a true difference in toxicity. This uncertainty is defined as Type I error (rejection of the null hypothesis when it is true; i.e. a false positive) and Type II error (acceptance of the null hypothesis when it is false; i.e. a false negative). The probability of correctly rejecting the null hypothesis is known as the power of the test, or 1-Type II error. Both Type I and Type II decision criteria should be established by evaluating the implications of making false positive versus false negative decisions (e.g., falsely concluding test sediment or elutriate is not toxic when it is).

Precision of sediment bioassay. Precision of such bioassays is good (Burton et al. 1996); therefore, the magnitude of uncertainty is low and can be easily quantified.

Interpretation of sediment bioassay. Because interpretation of the assay is based on comparison with a reference sediment, the magnitude of uncertainty can be estimated easily using statistics. The magnitude of uncertainty will depend on the sample size used for the bioassay.

\section{Benthic bioaccumulation}

Bioavailability from sediments. Body burdens of contaminants are of concern for both ecological and human health reasons. Benthic bioaccumulation tests determine the bioavailability through 28 -day exposures to whole sediments. 
The bioaccumulation potential must be demonstrated to be in compliance with the regulations before a dredged material can be considered to be acceptable for placement in an unrestricted open-water disposal site.

Concentrations of contaminants in organisms should reach steady state by the end of the standard test (e.g., 28-day tests for organic contaminants). Where it is desirable to estimate the steady-state concentration of neutral organic contaminants, a correction can be made to estimate the concentration at steady state. Steady-state concentrations of contaminants are compared in Tier III to applicable Food and Drug Administration (FDA) Action or Tolerance Levels for Poisonous or Deleterious Substances in Fish and Shellfish for Human Food.

Tissue contaminant concentrations measured in the bioassay that are statistically lower than FDA Action levels, or for which there are no levels, are compared to tissue concentrations for organisms similarly exposed to reference sediment. If tissue concentrations of COCs in organisms exposed to dredged material do not statistically exceed those of organisms exposed to the reference sediment, the dredged material is predicted not to result in unacceptable bioaccumulation of contaminants in benthic invertebrates (although benthic toxicity must be considered). If tissue concentrations of COCs in organisms exposed to the dredged material do statistically exceed those of organisms exposed to reference sediments, the final determination of compliance is assessed by consideration of the following factors:

a. Number of species in which bioaccumulation from the dredged material is statistically greater than bioaccumulation from the reference material.

b. Number of contaminants for which bioaccumulation from the dredged material is statistically greater than bioaccumulation from the reference material.

c. Magnitude by which bioaccumulation from the dredged material exceeds bioaccumulation from the reference material.

d. Toxicological importance of the contaminants whose bioaccumulation from the dredged material statistically exceeds that from the reference material.

$e$. Phylogenetic diversity of the species in which bioaccumulation from the dredged material statistically exceeds bioaccumulation from the reference material.

f. Propensity for the contaminants with statistically significant bioaccumulation to biomagnify within aquatic food webs.

g. Magnitude by which contaminants whose bioaccumulation from the dredged material exceeds that from the reference material also exceed the concentrations found in comparable species living near the proposed site.

Uncertainties associated with benthic bioaccumulation bioassays include the following: 
a. FDA Action Levels have been established for less than 20 chemicals. Therefore, risk associated with chemicals for which Action Levels have not been established cannot be estimated by this approach.

$b$. FDA Action Levels are based on economic as well as human health considerations, but do not indicate the potential for adverse impact to contaminated benthic organisms, or biomagnification and impact to higher trophic level organisms.

c. There is a lack of toxicity end points that relate body burdens in invertebrates to toxic effects. For example, measured body burdens of metals in benthic invertebrates are not well correlated with adverse effects to the invertebrates since many organisms can store metals in inert granules or other inactive storage forms. However, USACE has developed an Environmental Effects Residue Database (ERED), http://www.wes.army.mil/el/ered. This database compiles and makes accessible information on tissue concentrations of contaminants that are associated with adverse ecological effects or, in some cases, with no adverse effects.

The interpretation of the benthic bioaccumulation bioassays relies on testing differences between bioaccumulation in the reference sediment and in the dredged material. This type of testing involves balancing Type I and Type II errors (Parkhurst 1990; Suter 1993). Ideally, the power of the test (i.e., the probability of correctly rejecting the null hypothesis, defined as 1-Type II error) should be used to evaluate the magnitude of the uncertainty in the results. The magnitude of uncertainty associated with the sediment bioaccumulation test is ranked moderate given the range of BSAFs in the USACE database. Uncertainty as to how well the bioassay predicts the bioaccumulation of contaminants could be easily quantified by comparison of bioaccumulation observed in tests to the amount of bioaccumulation observed in field validation programs.

Food chain trophic transfer fish. Trophic transfer and biomagnification are considered only if bioaccumulation in the dredged material statistically exceeds bioaccumulation in the reference sediment. The magnitude of uncertainty is high for estimating biomagnification in fish, since degree of biomagnification depends upon a thorough knowledge of food chain dynamics in the ecosystem under consideration (Kidd et al. 1995; Oliver and Niimi 1988). Uncertainty in model predictions of food chain bioaccumulation can be quantified by comparison with results from field studies (Scott and Trowbridge 1995). Performing sensitivity analysis of the input parameters for bioaccumulation models can also provide information on the magnitude of uncertainty (Burkhard 1998; Iannuzzi et al. 1996).

Food chain trophic transfer piscivorous birds. Trophic transfer and biomagnification are considered if bioaccumulation from the dredged material statistically exceeds bioaccumulation from the reference sediment in the bioaccumulation test. Risks associated with trophic transfer and biomagnification of contaminants to higher trophic level organisms can be predicted by using models or empirically determined biomagnification factors (BMF). For example, a BMF of 30 was measured for the increase in concentrations of persistent 
organic contaminants in piscivorous birds and their prey (Jones et al. 1993). Estimation of the potential dose or body burdens in higher trophic level organisms may produce less conservative estimates of risk than simple statistical comparisons of body burdens in invertebrates exposed to dredged and reference sediments. For example, in some cases, bioaccumulation of significantly higher body burdens of contaminants from dredged sediment may not necessarily result in risk to higher trophic levels.

The magnitude of uncertainty associated with potential biomagnification in birds is ranked high. This ranking is based on the general lack of data on this topic. This source was given a moderate ranking for ability to reduce uncertainty because no models that predict body burdens are available and data are limited.

\section{Tier IV Evaluation}

A Tier IV evaluation is performed when a decision regarding toxicity or bioaccumulation has not been reached in lower tier evaluations. Tier IV involves case-specific, state-of-the-art testing for toxicity and/or bioaccumulation. Toxicity identification evaluation procedures can also be used in this tier, especially with sediments for which ammonia or hydrogen sulfide could be responsible for toxicity. If these approaches do not provide adequate information to make a determination, a complete risk assessment can be performed.

\section{Tier IV chronic bioassays}

In Tier IV, water column and sediment bioassays may be conducted if the Tier III bioassay results lead to an equivocal interpretation. Tier IV tests typically differ from Tier III tests in the following ways:

a. Longer duration of exposure (chronic bioassays).

b. Different species.

c. Different end points (sublethal effects).

d. In situ exposure.

COCs that adsorb to sediment particles quickly settle to the bottom. Therefore, sediment bioassays are an important test system for investigating adverse effects of chronic exposure to dredged material contaminants. Tier IV bioassays evaluate health end points resulting from chronic exposure. Potential sublethal end points include growth, reproduction, behavior, immunotoxicity, genotoxicity, etc. The interpretation of Tier IV bioassays may be difficult if the relationship between sublethal effects and population-level effects is not well understood or cannot be established.

Several chronic bioassays are under development for use in the evaluation of dredged material (Bridges and Farrar 1997; McGee, Schlekat, and Reinharz 1993). These bioassays more closely approximate field conditions and measure 
subtle sublethal end points related to the maintenance of a viable population. The interpretation of chronic bioassays should clearly define the relationship between chronic sublethal end points, such as growth, to population end points, such as survival and reproduction (Moore and Dillon 1993).

Population or demographic modeling is one method that can be used to interpret the results of chronic bioassays (U.S. Army Engineer Waterways Experiment Station (USAEWES) 1993). These models use life history information (e.g., survival, growth, reproductive rates) to make projections about potential population-level impacts (e.g., abundance over time). Using these models in conjunction with chronic bioassay results, one can compare estimated rates of population increase for dredged material and reference sediment.

Population modeling requires information on survivorship and fecundity of the target population, information that can be obtained from well-designed laboratory studies. In the environment, however, species are subject to both biotic and abiotic forces contributing to their ability to reproduce, grow, and survive.

As with previous tiers, Type I and Type II error is involved in the comparison between reference and dredged sediments. In addition, the analytical form of the population model introduces model uncertainty, and estimates of survivorship and fecundity introduce both variability and parameter uncertainty. Variability can typically be addressed in the population model by using a stochastic framework. One existing approach (Ferson 1991) models environmental stochasticity through (a) random fluctuations in age- or stage-specific fecundities and survivorships, (b) random fluctuations in carrying capacities (the maximum sustainable population), (c) random fluctuations in dispersal rates, and (d) two types of local or regional catastrophes.

The variability of each vital rate and carrying capacity is modeled with a standard deviation. Each population can have a separate set of standard deviations. The random fluctuations can be normally or lognormally distributed, and can be correlated among populations. Within a population, survivals, fecundities, and carrying capacities can be uncorrelated, perfectly correlated, or negatively correlated. Descriptive statistics such as standard deviations on the vital rates are obtained from the bioassay data; however, these values incorporate both uncertainty (measurement error) and variability (population heterogeneity).

First-order uncertainty analysis within a matrix framework can be used to evaluate confidence in the predictions. Other options available for evaluating uncertainty include the following:

a. Examine "within year" or "within season" measurements to estimate measurement error.

$b$. Examine "among year" or "among season" measurements to estimate variability.

c. Conduct a sensitivity analysis on each of the parameters in the population model to evaluate the range of possible results predicted by the model. 
d. Conduct a two-stage nested modeling process, in which variability and uncertainty are explicitly considered (USEPA 1996c).

\section{Uncertainties of Tier IV evaluation}

The following uncertainties are associated with the Tier IV evaluation:

a. Uncertainty in the results of chronic bioassays may result from the influence of nontreatment effects such as food ration (Bridges, Farrar, and Duke 1997).

$b$. Extrapolating from chronic bioassay results to predictions of population level impacts. Population models address this uncertainty to some extent, but are enhanced by field verification (Barnthouse, Suter, and Rosen 1990; Kuhn et al. 1997a, 1997b).

c. Population modeling typically addresses one species at a time, although analytical methods exist for considering species interactions and multiple species (Ferson 1991).

d. Uncertainty (measurement error) and variability (true population heterogeneity) are combined in the results from the bioassays, making it difficult to conduct an explicit uncertainty analysis in the context of population modeling.

Uncertainty associated with bioassay precision. The magnitude of the uncertainty that is associated with the results of the chronic bioassays can be greater than an order of magnitude (Bridges, Farrar, and Duke 1997). However, the uncertainty is easily quantified by conducting carefully controlled experiments.

Uncertainty associated with bioassay interpretation. Experimental (Kuhn et al. 1997a) and statistical methods (Meyer et al. 1986) have been developed for calculating the uncertainty associated with the estimation of population-level effects, and quantification of the uncertainty is ranked as moderate. The magnitude of uncertainty associated with the interpretation of the chronic bioassays is also expected to be moderate (Barnthouse, Suter, and Rosen 1989; Suter 1993).

Tier IV evaluations may further consider human and ecological health concerns by conducting water column evaluations, benthic evaluations, or risk assessments. Risk assessment provides a framework for considering multiple lines of evidence regarding the potential for contaminants to cause adverse effects. Uncertainties considered in the risk assessment process are discussed in the following section. 


\section{Uncertainty in Tier IV Risk Assessments}

\section{Problem Formulation/Hazard Identification}

This section discusses uncertainties associated with the problem formulation phase of the risk assessment process. Problem formulation is a planning phase that evaluates the nature of the problem and identifies the major factors to be considered in the assessment. Initial characterization of potential exposure pathways and receptors occurs in this phase. Assessment and measurement end points for ecological receptors are also identified. The outcome of the problem formulation/hazard identification phase is a conceptual model describing contaminant sources, migration pathways, exposure potential, and human and ecological receptors of concern.

Uncertainty is considered in a qualitative sense at the problem formulation phase, compared to the statistical or mechanistic approaches used to address uncertainty during the exposure and effects assessments. For example, there may be uncertainty in the selection of specific receptors or assessment end points, which is more difficult to quantify than other areas of uncertainty. Consequently, each source of uncertainty in the problem formulation phase is not ranked in Table 1.

\section{Development of conceptual model}

The conceptual model is a representation, sometimes graphical, which describes chemical sources, release mechanisms, exposure media and pathways, uptake routes, and receptor populations. Conceptual model development may be one of the most important sources of uncertainty in a risk assessment (USEPA 1998a). Uncertainty may arise from lack of knowledge about how the ecosystem functions, failure to identify secondary effects such as increased levels of predation, and lack of information about how stressors move through the environment and cause adverse effects (USEPA 1998a). The conceptual model is critical to defining subsequent analyses.

Characterization of the surrounding environment. The characteristics of the environment surrounding the site must be understood and described so that all potential exposure pathways and receptors are included in the conceptual model (U.S. Army Engineer Division, Huntsville, 1995). The following characteristics may influence exposures: 
a. Hydrodynamics. The depth, tidal range, and flow characteristics of the site may influence the potential for resuspension and transport of dredged sediment.

b. Climate. The temperature and precipitation profile of the area may limit the frequency of exposure, as well as the extent of chemical migration (e.g., fewer people fishing near a disposal site during the winter months).

c. Meteorology. Wind may transport particles and airborne contaminants (e.g., fugitive dust from a barge).

d. Sediment type. The grain size, organic carbon, and clay content may influence the leaching potential, resuspension of material during filling, and bioavailability of sediment contaminants.

e. Ecological. Characteristics of potentially exposed biota may include the numbers and types of receptors, their life histories, foraging and migratory habits, and the trophic structure of the food web. Food webs with a greater number of trophic levels can exhibit greater biomagnification to higher trophic level organisms, such as piscivorous (fish-eating) birds (USAEWES 1995).

The magnitude of uncertainty associated with characterizing the surrounding environment is ranked high given the complexity of ecosystems (Odum 1971). Uncertainty associated with characterizing the environment is difficult to quantify.

\section{Identification of complete and incomplete exposure pathways.}

Uncertainties in identification of complete and incomplete exposure pathways can arise from lack of information about dredging operations or about the site. For example, information about the presence of migratory species at a site may not be available. Exclusion of any complete exposure pathways would result in an underestimate of risk.

It is typically straightforward to assess the effect of an incomplete or excluded pathway by rerunning the analysis to include the pathway to determine the relative risk of each pathway.

\section{Selecting and characterizing representative ecological receptors. Most} ecosystems are complex and not all trophic levels and species can be considered during a risk assessment. Therefore, a few species are selected as indicators of environmental conditions. Various criteria have been developed for selecting ecological receptors of concern. For example, selected species should be distributed in the area under consideration, sensitive to the effects of the contaminants of concern, and representative of a group of important species to humans or to the functional integrity of the ecosystem (USEPA 1993c).

However, significant uncertainty arises from the fact that little to no data are available for some receptors in terms of sensitivity to contaminants, feeding preferences, migration, etc. For example, contaminant dose response information is unavailable for many marine mammals and marine reptiles. Exclusion of 
potentially sensitive organisms due to lack of data contributes to the uncertainty of the dredged material assessment.

\section{Assessment and measurement end points}

Selecting assessment end points. Assessment end points are defined as environmental characteristics or values that are to be protected, such as abundance of a wildlife population, species diversity, or ecosystem productivity (Suter, Barnthouse, and Bartell 1992). Lack of information with which to develop assessment end points for some COCs is an important source of uncertainty for the risk assessment.

In the conceptual model development stage, the uncertainty in selection of appropriate assessment end points is not quantifiable, but clearly has the potential to exert a significant influence on the direction of the analysis.

Selecting measurement end points. Measurement end points are quantitative expressions of a biological response that are related to the assessment end points. Measurement end points for ecological risk assessment are usually related to the survival, growth, and reproduction of receptors of concern. These measurement end points are assumed to be closely related to assessment end points, such as changes in population structure and function. The correlation of stressor to response is an indication of the strength of the relationship.

In some cases, assessment and measurement end points are closely related. For example, fish that consume contaminated prey in the area of a dredged material disposal site might accumulate body burdens of persistent chemicals, such as organochlorine compounds, which might subsequently accumulate in the eggs of fish-eating colonial birds. The amount of contaminant in the egg is a measurement end point that has been linked to embryolethality (measurement end point) and reproductive failure (assessment end point) in exposed populations (Giesy, Ludwig, and Tillitt 1994). However, measurement end points and assessment end points are not always so clearly related. For example, appearance of lesions or tumors on older adult fish may have little impact on the reproductive success of the population.

Uncertainty in the relationship between assessment and measurement end points can contribute to significant uncertainty in estimates of risk to the receptors. For example, consensus has not been reached on the appropriateness of existing and proposed assays to detect the potential for endocrine disruption properties of chemical substances and mixtures (Kendall et al. 1995). The results of an expert panel on ecological risk assessment for sediments found that the ecological relevance of measurement end points involving organic extracts and elutriates was most uncertain relative to other toxicity tests (Ingersoll et al. 1997).

Lack of measurement end points. In some cases, measurement end points will not be available. For example, although ERED provides information on the critical body burden of some chemicals, it does not contain information for all potential COCs. This information could be obtained through additional data collection and analysis, but is typically beyond the scope of a site-specific risk assessment. 


\section{Exposure Assessment}

This section discusses uncertainties that are associated with the exposure assessment portion of a risk assessment. The exposure assessment identifies potential exposure pathways and estimates the extent and magnitude of exposure in a defined field of influence.

\section{Estimation of exposure point concentrations}

The concentrations of COCs in various environmental compartments (e.g., air, water, and sediment) are used in the exposure assessment phase of the risk assessment to predict exposure to various human and ecological receptors. These concentrations are measured, estimated from laboratory tests, or predicted from models. When data are available, exposure point concentrations can be expressed as arithmetic averages or 95 percent upper confidence limits. The 95 percent upper confidence limit is an estimate of the upper bound on the mean with 95 percent confidence (i.e., there is a 95 percent chance that the true mean will be less than the estimated number). In some cases, the calculated 95 percent upper confidence limit will exceed the maximum detected concentration. Summary statistics on available data provide an indication of the measured variability in samples of dredged material. These estimates are typically less robust when based on small sample sizes.

If the initial screening level estimate exceeds a criterion, standard, or known toxic concentration, fate and transport models incorporating site-specific parameters are typically used to refine the estimates. The following section describes the uncertainties associated with the estimation of exposure point concentrations using fate and transport models.

Fate and transport models: model uncertainty. A variety of fate and transport models exist that estimate the amount of contaminant that can be released from various dredged material disposal alternatives to the surrounding environment. These models may predict new exposure point concentrations in space, time, or in other media, (e.g., air), or may simply predict the mass of COC that is lost from a source. For example, some contaminant may be lost in effluent from an island CDF. The Assessment and Remediation of Contaminated Sediments (ARCS) Program of the USEPA has published the guide, Estimating Contaminant Losses from Components of Remediation Alternatives for Contaminated Sediments" (USEPA 1996a). This report presents techniques for estimating contaminant losses associated with various sediment management alternatives. The techniques include laboratory tests and contaminant transport models. The models estimate contaminant losses during dredging, dredged material transport, pretreatment, and effluent and leachate treatment, and from CDFs. The report evaluates the relative reliability of the available predictive techniques, but does not include a statistical analysis of the uncertainty associated with using the various techniques.

Potentially one of the most significant sources of uncertainty in risk assessment is error associated with fate and transport models (Suter 1993). Model error arises from the inappropriate selection or aggregation of variables, incorrect 
functional forms, and incorrect boundaries. There are no straightforward statistical or mathematical techniques for describing this source of uncertainty as with other forms of uncertainty. The most efficient and appropriate method of assessing model error is to obtain field verification or conduct an experiment to validate the model. Table 1 describes the magnitude of uncertainty for these models as MS because the amount of uncertainty will vary from model to model.

Alternatively, the use of several different models using the same data is a suitable cross-validation method. Although this does not represent a quantifiable assessment of uncertainty, the fact that several models all lead to the same conclusion provides confidence that the models are performing correctly. Differences in model results can highlight mechanistic or parameter-based differences in each of the models, which may allow a determination of the appropriateness of one model over another. Bayesian approaches to comparing models also exist (Suter 1993).

Fate and transport models: Parameter uncertainty. The fate and transport models that are typically used in the dredged material management program obviously contain numerous parameters. Although it is beyond the scope of this report to examine the uncertainty associated with all of these parameters, the contribution of a few of the important parameters that are used in many of the models is considered in the following sections.

Physical-chemical attributes of COCs. Physical-chemical attributes of COCs are important parameters that are used in many fate and transport models to predict exposure point concentrations. These parameters, which help predict partitioning among media, often drive the predicted distribution of a contaminant in the environment.

Uncertainty in these parameters contributes to uncertainty in resultant exposure and risk assessments. Typically, physical and chemical property estimation depends on laboratory conditions (e.g., temperature, pressure, etc.). Consequently, a significant source of the uncertainty in using physical and chemical parameters in fate and transport models involves the applicability of a value for a given situation. For example, if a value is temperature dependent and there is a large disparity between the laboratory temperature under which the value was estimated and the expected field temperature, then the results of the model are likely to be wrong, reflected as uncertainty in the result. However, simplifying assumptions are inevitable and may be justified.

The contributions of physical and chemical properties to uncertainty in fate and transport models vary. For example, properties such as molecular weight, vapor pressure, and water solubility are straightforward to obtain and have less mathematical effect on the results of fate and transport models than properties such as $K_{o w}$ and $K_{o c}$. Therefore, the former properties are ranked low for magnitude of uncertainty with only moderate difficulty in reducing this uncertainty. The latter properties are ranked moderate in magnitude of uncertainty given that published values for particular chemicals can span one to two orders of magnitude (Mackay, Shiu, and Ma 1992a, 1992b). 
The octanol-water partition coefficient $K_{o w}$ describes the hydrophobicity of various organic COCs, and is used to predict the partitioning of these COCs between water and sediment. Because measuring the $K_{o w}$ of highly hydrophobic compounds can be technically difficult, a range of values, representing various techniques for measuring or modeling $K_{o w}$, have been reported for most organic COCs. For example, reported values for the $\log _{10} K_{o w}$ of benz[a]anthracene range from 5.61 to 7.50 (Mackay, Shiu, and Ma 1992a, 1992b). Comparisons of the results of various methods that are used to determine $K_{o w}$ indicate that the slowstir flask method has less variability and experimental bias and provides the best estimate of $K_{o w}$ (USEPA 1993b). Professional judgment must be used when selecting the $K_{o w}$ that will be used in a risk assessment. Consequently, uncertainties contributing to over- or underestimates of risk can occur.

The organic carbon-water partition coefficient $K_{o c}$ estimates the distribution of an organic contaminant between sediment organic matter and the freely dissolved phase in water, and is used to predict the concentrations of these COCs in water and sediment. The $K_{o c}$ of a compound can be measured or estimated from $K_{o w}$ based on a regression relationship (DiToro et al. 1991). Typically, the literature provides a range of values for $K_{o c}$ for an individual organic compound (Mackay, Shiu, and Ma 1992a, 1992b). For example, reported values for the $\log _{10} K_{o c}$ for benz[a] anthracene range from 4.0 to 7.30.

Professional judgment must be used when selecting the most appropriate value from the literature. As a result, uncertainties contributing to over- or underestimates of risk can occur.

Apparent values of $K_{o c}$ that are measured in field-collected sediments can be larger than predicted. For example, PAHs that are physically sequestered into soot particles may be less available for partitioning into soil- or sedimentassociated pore water, resulting in a $K_{o c}$ that is higher than predicted (Gustafsson et al. 1997). One study reported an apparent $K_{o c}$ for partitioning of phenanthrene between field-collected sediments and associated pore water that was almost three orders of magnitude greater than a $K_{o c}$ reported in the literature (McGroddy and Farrington 1995).

Alternatively, apparent values of $K_{o c}$ can be smaller than predicted if a greater amount of an organic contaminant partitions into the pore water than would be predicted based on the concentration in the sediment. Higher than expected concentrations of organic contaminants in the pore water are taken into account by a three-phase model, which includes partitioning of organic contaminants onto dissolved organic carbon (DOC), such as colloids (Brownawell and Farrington 1986). For example, the lowest reported apparent $\log _{10} K_{o c}$ for PCB-18 $(2,2$ ', 5-trichlorobiphenyl) in one field study was 3.05 (Brownawell and Farrington 1986), much lower than a value reported from the literature of 5.24 (Hawker and Connell 1988).

The dissolved organic carbon-water partition coefficient $K_{d o c}$ is an important parameter in the estimation of the partitioning of organic contaminants between the "freely dissolved" phase and the phase associated with DOC in water. It is generally believed that only chemicals in true solution (i.e., "freely dissolved") are bioavailable. Partitioning of a hydrophobic compound onto DOC reduces uptake of dissolved organic contaminants from water into fish 
(McCarthy and Jimenez 1985; Landrum et al. 1985) and invertebrates (McCarthy, Jimenez, and Barber 1985). Although considerable uncertainty exists in measured values for $K_{d o c}$, experimental data suggest that $K_{d o c}$ is approximately a factor of 10 less than the $K_{o w}$ of a chemical (Landrum et al. 1984).

Temporal considerations: Degradation of labile contaminants.

Approaches for estimating risk associated with disposal of dredged material often do not consider the potential for microbial biotransformation or other degradation processes (e.g., hydrolysis, photooxidation) that effect labile organic contaminants. Numerous studies have demonstrated the degradation of organic contaminants by microorganisms in pure culture and in natural sediments (Herbes and Schwall 1978; Cerniglia and Heitkamp 1989). When dredged sediments are removed from sources of contamination, concentrations of low molecular weight PAHs may decline significantly over time due to biodegradation that occurs at the disposal site. In this example, risk could be overestimated at the disposal site.

Prediction of the rate of degradation is uncertain because rates of microbial degradation can be affected by a variety of factors, including temperature, salinity, and adaptation of the ambient microbial community (Shiaris 1989). For example, rates of transformation of PAHS can be 3,000 to 125,000 times greater in contaminated sediments than in uncontaminated sediments (Herbes and Schwall 1978). This phenomenon can be quantitatively reflected by a biodegradation rate constant in a fate and transport model.

\section{Bioaccumulation of COCs}

Organisms can bioaccumulate and biomagnify dredged material contaminants from sediment and water. After the fate and transport of contaminants in the environment are estimated, bioaccumulation potential is evaluated.

A variety of models are used to estimate the bioaccumulation of COCs. In these models, exposures can be estimated for upper trophic level receptors. For aquatic organisms, models that predict the concentration of COCs in tissues of exposed organisms are usually used (Gobas 1993; Thomann 1989). These models predict concentrations of COCs in benthic invertebrates and in higher trophic level fish. For semiaquatic organisms, models that predict a daily dose of COCs are typically used (Opresko, Sample, and Suter 1994). Models are also available that relate contaminant concentrations in prey to concentrations in eggs of fisheating birds in the form of biomagnification factors. Human-based exposure models typically predict a daily dose of COCs (USEPA 1992). Uncertainties associated with each approach are described in the following sections.

Bioavailability of contaminants from sediment for ecological receptors. Sediment bioaccumulation tests are used in Tier III to measure accumulation of contaminants from samples of dredged material (USEPA/USACE 1991, 1998). USACE has developed a database from these sediment bioaccumulation tests and other sources that demonstrates the variability in reported BSAFs (htttp://www.wes.army.mil/el/t2dbase.html). Unfortunately, no theoretical framework exists for predicting bioaccumulation of metals or polar organic chemicals from sediment. This could be a major source of uncertainty in the risk 
assessment process because bioaccumulation information is a key element in assessing risk. Therefore, this category receives a moderate ranking in Table 1 . Sediment bioaccumulation tests, can, however, be used to directly and easily measure the potential for bioaccumulation of these compounds from sediment.

Bioavailability of contaminants from water for ecological receptors. Adsorption of hydrophobic COCs onto DOC in surface waters reduces bioavailability (Landrum et al. 1987; McCarthy and Jimenez 1985). Kinetic limitation to accumulation of hydrophobic COCs into phytoplankton may reduce bioavailability of COCs from water (Swackhamer and Skoglund 1993). Partitioning of hydrophobic COCs onto DOC can be easily estimated, if measurements of the concentration of DOC are available. However, kinetic limitations to uptake in phytoplankton are more difficult to predict. Because of this uncertainty in the uptake kinetics, this category is given a ranking of moderate uncertainty that is moderately difficult to quantify.

Exposure models for aquatic organisms: model uncertainty. Several models are available for predicting concentrations of contaminants in tissues of exposed organisms from concentrations in the environment. Two models that are often used to predict tissue concentrations from concentrations in sediment are the models of Gobas (1993) and Thomann (1989). These models estimate steadystate concentrations of hydrophobic organic substances in various aquatic organisms. In these models, fish absorb chemicals directly from water via the gills and through the consumption of food via the gastrointestinal tract. Chemicals are lost via the gills to the surrounding water, via egestion of fecal matter, and by metabolism. Growth of the fish also results in dilution of tissue concentrations and is modeled as a loss process.

Presently, why the ability to metabolize organic xenobiotics varies among taxonomic groups is not understood (Nebert, Nelson, and Feyereisen 1989), and few models can estimate the rate of metabolism and elimination of these contaminants. For some persistent organochlorine chemicals, the rate of metabolism is small compared to the rate of uptake or elimination via other routes, and metabolism can be ignored. For other chemicals, such as PAHs, which are readily transformed by fish, use of the Gobas (1993) and Thomann (1989) models without consideration of metabolism is not recommended. This is a large source of uncertainty in the use of these models in risk assessment. Risk to a receptor could be overestimated if actual body burdens of PAHs, for example, were lower than predicted due to metabolism. Alternatively, risk could be underestimated when metabolites accumulate in tissue and exert a greater toxic effect than the unmetabolized parent compound.

a. Equilibrium models and time-varying conditions. Equilibrium conditions are often used to predict bioaccumulation of contaminants from sediment and water into aquatic organisms, such as in the Gobas (1993) and Thomann (1989) models. These steady-state models provide an analytical solution to time-varying models under the assumption that contaminant concentrations are constant $(d C / d T=0)$. These models may be appropriate for estimating long-term expected concentrations of contaminants, but will not be suitable for episodic events. 
Very little information is available on how often contaminants in the environment reach equilibrium among phases. If equilibrium conditions are not reached, time-variant models are more appropriate for predicting contaminant concentrations. The distributions of contaminant concentrations might differ from predicted concentrations if the system is not in equilibrium because there is high temporal variability or because biological processes maintain disequilibrium conditions. Many ecosystem and physical processes are variable over time. The input of a contaminant into an estuary, for example, can occur during episodic events, such as large storms or periodic disposal of dredged sediments. An example of biological processes that result in deviations from equilibrium conditions would be the detoxification of metals in tissues of animals by sequestration into granules. The quantitative importance of the uncertainty associated with the use of equilibrium models, rather than time-variant models, can be significant (Ludwig et al. 1993; USEPA 1996b), and is ranked MS in Table 1, because the significance will vary from model to model.

b. Parameter uncertainty in uptake models. The Gobas (1993) and Thomann (1989) exposure models require a variety of input parameters that are derived from various sources. For example, some are based on observed allometric relationships. Others are based on observed relationships to the physical/chemical characteristics of the COC. Uncertainty associated with these parameters will contribute to uncertainty in tissue concentrations and risk estimates. An overall estimate of the contribution of these models to uncertainties in the risk assessment is provided at the end of this section. The individual parameters have moderate magnitudes of uncertainty and moderate difficulty for reducing uncertainty because they vary from site to site and can be measured only with substantial effort. For humans, these parameters can be very difficult to measure when appropriate biomarkers are not available and they vary from one contaminant to the next.

The Gobas (1993) model assumes that fish take up chemicals from the water (via the gills) and through the consumption of food. Loss of chemicals occurs via the gills to the water, via egestion of fecal matter, or by growth of the organism, which dilutes its concentration. The Gobas model uses various assumptions to estimate these uptake and loss rates. Uncertainty in these estimates will contribute to uncertainty in estimates of exposure and risk to the fish and its consumers. The following section discusses the importance of parameter uncertainty for the following parameters of the Gobas model: uptake from water, uptake from food, ingestion and elimination, and growth rates.

(1) Uptake from water. The rate at which fish take up chemicals from water depends upon the gill ventilation rate and the rate of diffusion of the chemical across the gills. The Gobas (1993) model uses experimental data to derive uptake rates based on the following:

(a) $K_{o w}$ of the compound. 
(b) Weight of the fish $V_{F}, \mathrm{~kg}$.

(c) Rate of chemical transport in the aqueous phase of the gill $Q_{w}$, in units of L/day.

(d) Rate of chemical transport in the lipid phase of the gill $Q_{L}$, in units of L/day.

The uncertainty associated with $Q_{w}$ and $Q_{L}$ is expressed by the range on the exponential term in the equation for $Q_{w}$ :

$$
\begin{aligned}
& Q_{w}=88.3 \times V_{F}^{0.6( \pm 0.2)} \\
& Q_{L}=Q_{w} / 100
\end{aligned}
$$

Uncertainty in the uptake rates $\left(Q_{W}\right.$ and $\left.Q_{L}\right)$ will contribute to uncertainty in fish body burden estimates and estimates of risk to the fish and their consumers.

(2) Uptake from food. The rate at which fish take up chemicals from food depends upon the food ingestion rate, the rate of diffusion of the chemical across the intestinal wall, and the fecal egestion rate. The Gobas model (1993) assumes that the efficiency with which chemicals are taken up from food is related to the transport of chemicals across aqueous and lipid phases of the gut:

$$
1 / E_{D}=A \times K_{o w} \times B
$$

where

$E_{D}=$ the uptake efficiency from the diet (fraction)

$A=$ a constant relating to the transport rate of the chemical in the aqueous phases of the fish

$B=$ a constant relating to the transport rate of the chemical in the lipid phase of the fish

According to a nonlinear regression of available data, $A$ is 5.3 $\left.( \pm 1.5) \times 10^{-8}\right)$, and $B$ is $2.3( \pm 0.3)$. Uncertainty associated with these estimates could contribute to uncertainty associated with estimates of body burdens in fish and estimates of risk to the fish and their consumers. The magnitude of uncertainty could be evaluated by performing a sensitivity analysis on the input parameters.

(3) Ingestion and elimination rates. The Gobas model (1993) expresses the rate at which chemicals are eliminated through fecal egestion, as the fecal elimination rate constant $k_{E}$. Available data show that the fecal egestion rate is approximately 3 to 5 times lower than the ingestion rate. Therefore, the model assumes that 


$$
k_{E}=0.25 \times k_{D}
$$

where $k_{D}$ is the dietary uptake rate constant. In the environment, there is variability between species, locations, and seasons in the actual rates and uncertainty in applying rates from the literature to field conditions at a particular site.

(4) Growth rates. No uncertainty is reported for the equations used for generalized growth of fish (Thomann, Connolly, and Parkerton 1992):

$$
\begin{array}{ll}
k_{G}=0.00251 \times V_{F}^{-0.2} & \text { for temperature around } 25^{\circ} \mathrm{C} \\
k_{G}=0.000502 \times V_{F} & \text { for temperatures around } 10^{\circ} \mathrm{C}
\end{array}
$$

where

$$
\begin{aligned}
& k_{G}=\text { the growth rate constant } \\
& V_{F}=\text { the wet weight of the fish, } \mathrm{kg}
\end{aligned}
$$

(5) Sensitivity analysis for food-chain models. Each of the bioaccumulation models uses a set of parameters to predict the body burdens of organic contaminants in higher organisms. The uncertainty associated with these parameters contributes to the uncertainty of the risk estimate. Burkhard (1998) compares the sensitivity of the Gobas (1993) and Thomann (1989) model outputs to changes in input parameters. Sensitivity of the models was determined by running each model once with nominal input values, changing one input value by 10 percent, and running the model with the altered input value. A sensitivity of 1.0 means that a 10 percent change in the input parameter resulted in a 10 percent change in the model output. In this case, the model output examined was the Bioaccumulation Factor (BAF), which is equal to the ratio of the lipid-normalized concentration of chemical in fish to the concentration of freely dissolved chemical in water.

For both models, the input parameters with the largest influences were

(a) Lipid contents of the organisms.

(b) $K_{o w}$ of the chemical.

(c) Ratio of the concentration of chemical in sediment organic carbon to the concentration in overlying water $\Pi_{S O C W}$.

(d) Feeding preferences of the organisms (only for chemicals with $\log K_{\text {ow }}$ exceeding 6). 
Sensitivities ranged up to about -20 (indicating a decrease in BAF) for the feeding preference of a benthic invertebrate on phytoplankton in the Thomann model. The models were less sensitive to changes in organism weight, temperature (input to Gobas model only), and sediment organic carbon (input to Gobas model only).

As described (Burkhard 1998), the uncertainty associated with the model output depends not only upon its sensitivity to the input parameters described but also on the uncertainty associated with the individual input parameters. For example, a low sensitivity input parameter can add considerable uncertainty to estimates of output if the measurement uncertainty of the input is relatively large.

Uncertainty associated with the input parameters may result from analytical errors in the measurement of the parameter, sampling that is not representative of the population, or lack of sufficient information about the parameter.

The dual influences of sensitivity and uncertainty in the input parameters must be considered when evaluating the overall model uncertainty. Monte Carlo simulations were performed for each input parameter, using a plausible range of values for each input parameter that reflect uncertainty, not variability (Burkhard 1988). The ratios of the $90^{\text {th }}$ and the $10^{\text {th }}$ percentiles of the model output derived from the simulations were compared among input parameters. For both models, $\Pi_{S O C W}, K_{o w}$, and feeding preferences resulted in the largest range of simulated output values. Table 2 summarizes results from Burkhard (1998).

\begin{tabular}{|c|c|c|c|}
\hline \multicolumn{4}{|c|}{$\begin{array}{l}\text { Table } 2 \\
\text { The Ratio of the } 90^{\text {th }} \text { to the } 10^{\text {th }} \text { Percentile of Bioaccumulation } \\
\text { Factors (BAF) Predicted by the Gobas and Thomann Models for a } \\
\text { Piscivorous Fish for a Log } n-\text { Octanol/Water Partition Coefficient } \\
K_{\text {ow }} \text { of } 6.5 \text { Using the Uncertainties of the Individual Input } \\
\text { Parameters }\end{array}$} \\
\hline \multirow[b]{2}{*}{ Parameter } & \multirow{2}{*}{$\begin{array}{l}\text { Input Parameter } \\
\text { Uncertainty } \\
\text { (C.V.), \% } \\
\text { (assumed } \\
\text { distribution) }\end{array}$} & \multicolumn{2}{|c|}{$\begin{array}{c}\text { Ratio of } 90^{\text {th }} \text { to } 10^{\text {th }} \\
\text { Percentile Predicted } \mathrm{BAF}_{I}^{f d}\end{array}$} \\
\hline & & Gobas Model & Thomann Model \\
\hline$K_{\text {ow }}$ & 0.2 (lognormal) & 1.41 & 2.88 \\
\hline Temperature & 10 (normal) & 1.15 & Not used \\
\hline Sediment organic carbon & 63 (normal) & 1.00 & Not used \\
\hline$\Pi_{\text {socw }}$ & 15 (lognormal) & 3.09 & 2.19 \\
\hline Weight of piscivorous fish & 50 (normal) & 1.05 & 1.00 \\
\hline $\begin{array}{l}\text { Lipid content of piscivorous } \\
\text { fish }\end{array}$ & 5 (normal) & 1.12 & 1.10 \\
\hline $\begin{array}{l}\text { Feeding preference of smelt } \\
\text { (fish) }\end{array}$ & 40 (normal) & 1.58 & 1.05 \\
\hline
\end{tabular}


Note, however, that the findings of Burkhard (1998) are based on the analysis of a Great Lakes food web in which benthic organisms are an important food source for higher trophic level organisms. In food webs where the benthic component is less important, the importance of the input parameters on the uncertainties associated with predicted output parameters will be different.

Iannuzzi et al., (1996) developed probabilistic distributions for several important parameters that are typically used in mechanistic bioaccumulation models to predict the uptake of organic contaminants in aquatic food webs. The ranges, central tendencies, and distributions of key parameters of the models were derived from a critical evaluation of the literature on the physiology and ecology of three common estuarine organisms. Distributions of the physical/chemical characteristics (i.e., the octanol-water partition coefficient $K_{o w}$ ) for several congeners of PCBs were also compiled from the literature.

The model used by Iannuzzi et al. (1996) is based on a Monte Carlo version of the equations developed by Thomann, Connolly, and Parkerton (1992), and Gobas (1993). This model was used to estimate the concentrations of five coplanar PCB congeners in adult mummichog fish, blue crab, and striped bass, using distributions of available data on PCB and total organic carbon (TOC) concentrations that were measured in surface sediments from the Passaic River in northern New Jersey. A model sensitivity analysis was performed in order to measure and rank the sensitivity of the bioaccumulation model output (i.e., concentration of contaminant in fish and crabs) to each of the input parameters.

Results of the sensitivity analysis suggest that the following input parameters most influence the model (not listed in order of importance):

(a) BSAF (biota-sediment accumulation factor) for infaunal organisms.

(b) Lipid content.

(c) Chemical concentrations in sediment.

(d) TOC content of sediments.

(e) The chemical assimilation efficiency (CAE).

(f) Residence time in the river for striped bass.

(g) $\log K_{o w}$.

In summary, both Burkhard (1998) and Ianuzzi et al. (1996) concluded that the lipid content of the exposed organisms and the 
$K_{o w}$ of the contaminant influence estimates of tissue concentrations more than other parameters and are important to overall estimates of risk in the assessment. The magnitude of uncertainty associated with the use of these models for nonmetabolizable organic contaminants is generally thought to be low.

\section{Exposure models for semiaquatic organisms and humans: Model}

uncertainty. Semiaquatic organisms (e.g., piscivorous birds) may consume fish that have been exposed to contaminants from a disposal site. Inability of models to predict concentrations of metals or readily metabolized organic contaminants in tissues of higher trophic level organisms (e.g., eggs of piscivorous birds) is a significant source of uncertainty for assessing risk associated with dredging and disposal activities. Magnitude of the uncertainty will depend upon the specific model under consideration. The "moderate" ranking is given because numerous models are available to evaluate exposure but field studies would be needed to substantially reduce the uncertainty.

Exposure models for semiaquatic organisms and humans: Parameter uncertainty. Wildlife near open-water disposal sites could be exposed via oral, inhalation, or dermal routes of exposure. The Wildlife Exposure Factors Handbook (USEPA 1993c) tabulates data for various routes of exposure, with an emphasis on oral exposure. Oral exposures might occur via ingestion of contaminated food or water or incidental ingestion of soil or sediment during foraging activities. The Handbook provides quantitative information on various exposure parameters that can be used to estimate exposure of an animal to environmental contaminants. The Handbook separates exposure parameters conceptually into four types:

a. Normalizing parameters, such as body weight, growth rate and metabolic rate.

b. Contact rate parameters for oral exposure (dietary composition and ingestion rates of food, water, sediment/soil), exposure by inhalation (inhalation rate), and dermal exposure (surface area).

c. Population dynamic parameters, such as home range size, population density, fecundity, age at sexual maturity, mortality rate, average longevity.

d. Seasonal activity parameters, such as mating season, hatching, molting/metamorphosis, and dispersal/migration/hibernation.

Humans who work with the dredged material or consume impacted fish and shellfish might also be exposed. Exposure factors for humans are readily available (USEPA 1997a). Uncertainty associated with these exposure parameters is described in the following section.

a. Physiological characteristics. Physiological characteristics such as body weight, inhalation rate, and other parameters are necessary inputs for mechanistic-based bioaccumulation models. For wildlife, allometric relationships have been developed from empirical studies. For humans, 
empirical studies and pharmacokinetic modeling provide information to develop distributions and/or appropriate statistics for use in exposure models. The variability in physiological parameters is well understood and the magnitude of uncertainty is low.

b. Exposure duration. The following characteristics affect exposure duration:

(1) Feeding preferences. Because of lack of information about actual feeding preferences, screening-level risk assessments often conservatively assume that a receptor of concern feeds exclusively on a single prey item from the area of the disposal site. However, different species may have very different exposures and estimated body burdens of contaminants. For example, a fish that feeds on benthic invertebrates could consume polychaete worms that feed on highly contaminated sediment or a filter feeding clam that is exposed to lower concentrations of hydrophobic contaminants in overlying water. Uncertainty about feeding preferences will contribute to uncertainty in estimates of exposure and risk.

(2) Food and water ingestion rates. Because information on rates of ingestion of food and water will not be available for all receptors of concern, rates may be estimated from allometric relationships (USEPA 1993c). However, estimated values may not reflect actual rates for some species. For example, some species obtain more of their water from their diet and drink less water than other species. When available, measured values for ingestion rates of food and water should be used rather than estimated rates.

(3) Home range. Home range is defined as the geographic area encompassed by an animal's activities (except migration) over a specified time (USEPA 1993c). Home range size (also known as territory size or home range) can be used to estimate the proportion of time that an individual animal is expected to contact contaminated environmental media. In a screening-level risk assessment, the home range of the species of concern is often assumed to completely overlap the site under consideration, so that the predator takes all of its prey from the contaminated site. In actuality, the home range of the predator can be larger than the area of the site and only a fraction of the predator's total prey is taken from the site. Uncertainties in the actual home ranges of particular species can be significant. For example, home range size for individuals within a population can vary with season or latitude or as a consequence of changes in the distribution and abundance of food or other resources.

Typical home range sizes for commonly encountered terrestrial species, as summarized in the Wildlife Exposure Factor Handbook (USEPA 1993c), are presented in Table 3. 


\begin{tabular}{||l|l|l||}
\hline \hline $\begin{array}{l}\text { Table } 3 \\
\text { Range of Reported Home Range Sizes }\end{array}$ \\
\hline \hline $\begin{array}{l}\text { Common } \\
\text { Name }\end{array}$ & Scientific Name & $\begin{array}{l}\text { Range of Reported Values } \\
\text { for Home Range Size } \\
\text { square kilometers }\end{array}$ \\
\hline \hline Sandpiper & Actitis macularia & $\sim 0.0025$ \\
\hline River otter & Lutra canadensis & 2.95 to 4.0 \\
\hline Osprey & Pandion haliaetus & 9.1 to 314 \\
\hline
\end{tabular}

(4) Migration. A species that migrates away from the disposal site may have more limited exposure than a local nonmigratory species.

Migratory patterns could also bring a species under the influence of a dredged material management site during a particularly vulnerable life stage (i.e., breeding period, larval development, etc.). Such limited, but possibly critical, exposures may present significant sources of uncertainty in estimating exposure. Avoidance or attraction of wildlife to dredging or disposal sites also may influence their exposure to COCs.

Overall, a moderate degree of uncertainty is associated with parameters that describe the exposure duration of ecological receptors (USEPA 1993c). Additional information that would reduce this uncertainty could be obtained through field surveys and laboratory measurements.

(5) Time-activity patterns for workers. There is both uncertainty and variability in specifying the exact time-activity patterns of workers. Time-activity patterns are an important component of estimating exposures to contaminants in dredged materials. The most reliable estimates will be obtained based on site-specific information. With this information, the magnitude of uncertainty should be low and easily quantified.

\section{Effects Assessment}

\section{Toxicity end points for ecological receptors}

Toxicity end points for mammalian and avian species have been evaluated and compiled in "Toxicological Benchmarks for Wildlife: 1996 Revision" (Sample, Opresko, and Suter 1996). Relatively few of the studies included in this compilation determined safe levels (no observed adverse effect levels (NOAELs)) for exposures in which wildlife were chronically exposed over an entire lifetime or several generations. Although USEPA has no clear definition for the duration of a chronic exposure, some approaches assume that a chronic exposure is equal to at least 50 percent of a species' life span. In many cases, however, the only information available is from short-term or subchronic experiments on laboratory species (e.g., mice and rats). Estimating an NOAEL 
for chronic exposures from these data introduces varying levels of uncertainty into the risk assessment.

If an NOAEL is available for a test species $N O A E L_{t}$, then the equivalent NOAEL for a species of wildlife $N O A E L_{w}$ can be calculated by using an adjustment factor for differences in body size:

$$
N O A E L_{w}=N O A E L_{t}\left(b w_{t} / b w_{w}\right)^{1 / 3}
$$

where $b w_{t}$ and $b w_{w}$ are body weights of the test species and the wildlife species, respectively.

However, important differences between taxonomic groups may be overlooked by this approach. For example, one of the test species for the effects of 2,3,7,8-tetrachlorodibenzo-p-dioxin (2,3,7,8-TCDD) is the chicken (Opresko, Sample, and Suter 1994). However, the chicken is often listed as one of the most sensitive species to the effects of 2,3,7,8-TCDD-like compounds (USEPA 1994). Therefore, use of the chicken NOAEL to estimate effects in wild birds may overestimate the potential for risk. It is important for the assessor to consider the taxonomic relationship between the test species and the one of concern.

To predict adverse effects, one must know at what point during the life of an organism that exposure occurs. For example, for many species, exposure to certain chemicals during gestation may produce severe adverse effects on reproductive success.

\section{Toxicity end points based on body burdens}

Typical toxicity tests use concentrations of contaminant in an external medium, such as water or sediment, as a surrogate for actual dose to the organism. However, complex behavioral interactions between certain organisms and environmental media (e.g., benthic invertebrates and sediment) can confound approaches that attempt to predict exposure and adverse effects for sedimentdwelling organisms. Studies that relate measured body burdens of contaminants to toxic effects appear to have better predictive ability for some compounds (McCarty and Mackay 1991). Databases such as ERED (http:// www. army. mil/el/ered) that have been developed by USACE and others relate measured body burdens of chemicals to adverse effects. Comparison of measured body burdens in the field to levels known to produce adverse effects in similar organisms should decrease the uncertainty associated with estimates of risk to these receptors.

Another theoretical approach, the narcosis model (van Wezel and Opperhuizen 1995), shows promise for accurately predicting effects of chemicals that act as nonpolar narcotics. This approach predicts that, for fish with a lipid content of about 5 percent, narcosis should be observed at concentrations of 2 to $8 \mathrm{mmol}$ of narcotic chemicals per kg wet weight of animal. The range in expected toxicity is ascribed, at least in part, to interspecific variation in the lipid content of the animals. A more limited range in toxic body burdens is observed when the toxicity end point is based on a concentration in lipid of 40 to $160 \mathrm{mmol}$ of chemical per kg of lipid (van Wezel and Opperhuizen 1995). 
Because acute toxicity test data were used to develop and test this approach, ability of the narcosis model to predict effects from chronic exposures is less certain.

Overall, this source of uncertainty received a rank of high for magnitude of uncertainty because information relating body burdens of metals to toxic effects is limited and because the abilities of the various approaches to predict effects from chronic exposures have not been thoroughly tested. It would be moderately difficult to reduce this uncertainty given the complexity of interactions between organisms and environmental media.

\section{Human receptors: Dose-response models for carcinogens and noncarcinogens}

The dose-response assessment defines the relationship between the dose of a contaminant and an effect. Potential toxic effects of contaminants are categorized as either carcinogenic (cancer causing) or noncarcinogenic (acute, subchronic, or chronic systemic effects). The mechanisms, models, and toxicity factors derived for each of these categories differ. In both cases, high doses administered to experimental animals or obtained from exposure estimates in epidemiological studies are extrapolated to the low exposure levels expected in the environment. The uncertainty factors applied to toxicity factors range from 10 to 10,000 , leading to a magnitude of uncertainty ranking of high. It is possible, with moderate difficulty given that test subjects are human, to test the accuracy of individual uncertainty factors.

Potential carcinogens. The toxicity of a potential carcinogen is described by a cancer slope factor (CSF). The slope factor is based on the assumption that even a small number of molecular events can lead to changes in a single cell leading to uncontrolled cellular proliferation. In other words, unlike noncarcinogens, slope factors are derived by assuming that there is no concentration or dose threshold below which the carcinogen does not pose any risk. A slope factor is obtained by fitting a mathematical model to observed tumor-response data followed by an estimation of the slope out of the range of the data. Differing extrapolation procedures or models may lead to large differences in projected risk at low doses. In addition, uncertainty in the carcinogenic mechanism of a contaminant can make the choice of model more difficult.

Nonhuman animal data are often the only data available for deriving CSFs. Consequently, the equivalent human dose to the animal dose used in the study relies on the assumption that different species are equally sensitive to contaminant effects given the same dose per unit of body surface area absorption. (The calculation uses body weight raised to the $2 / 3$ power, since surface area has been shown to be proportional to this quantity.)

The USEPA Carcinogen Risk Assessment Verification Endeavor Work Group describes the level of confidence that should be attributed to cancer slope estimates (1998c). There is considerable uncertainty in the toxicity factors used to estimate human health risks. One method of quantitatively assessing the uncertainty involves constructing a probability density function by combining all the available animal and epidemiological data (McKone and Bogen 1992). This may be appropriate for contaminants where the mechanism of action is well 
understood. In the case of contaminants for which the mode of action is less clear, elicitation of a distribution through expert judgment can be used to quantify uncertainty (Evans et al. 1994).

Potential noncarcinogens. The toxicity of a potential noncarcinogen is described by a reference dose (RfD) for the ingestion route of exposure and a reference concentration (RfC) for the inhalation route of exposure. The reference dose is defined as an estimate (with uncertainty spanning perhaps an order of magnitude) of a daily exposure to the human population (including sensitive subgroups) that is likely to be without appreciable risk of adverse effects. Noncarcinogenic toxicity factors assume that a concentration or dose threshold exists, below which no adverse effects are expected.

The no-threshold assumption suggests there is a range of exposures from zero to a finite value that can be tolerated by individuals with essentially no chance of expression of the toxic effect. The goal is to determine the lowest of these exposures in an effort to protect the most sensitive members of the population. RfDs and RfCs are derived from an NOAEL from an appropriate animal study. The highest NOAEL is used if a range of studies are available. A number of uncertainty factors are applied to NOAELs to derive RfDs and RfCs to account for animal to human extrapolation, variation in human sensitivity, and varying toxicity data quality.

\section{Extrapolation}

In ecological risk assessment, uncertainty factors are used to compensate for differences among measurement end points in available test species and assessment end points in species of concern at a dredging or disposal site. Typically, these fractional factors vary inversely with the quantity and type of data available (USEPA 1998a).

In human health risk assessment, factors are used to reduce NOAELs to account for scientific uncertainty inherent in toxicity databases. These factors are applied to a Low Observed Adverse Effect Level (LOAEL) when an NOAEL is not available. Dourson and Stara (1983) provide some empirical justification for the use of these uncertainty factors, which are typically an order of magnitude for each type of uncertainty considered.

Intraspecies. For human noncarcinogenic toxicity values, a factor of 10 is applied to an NOAEL or LOAEL to account for the variation in sensitivity among members of the population.

Although natural variation contributes to uncertainty in estimates of ecological risk, uncertainties in toxicity end points (i.e., confidence intervals on $\mathrm{LC}_{50}, \mathrm{EC}_{50}$, or LOAEL) are generally not reported in the literature. In some cases, adaptation of individuals may result in differences in sensitivity between animals reared in the laboratory or wild animals that are exposed in the field. For example, recent work has documented populations of fish in the field that are resistant to the acute toxic effects of PAHs (van Veld 1997) and PCBs (Nacci et al. 1997). Overall, the magnitude of uncertainty associated with differences among individuals in a species is expected to be low. 
Interspecies. An additional factor of 10 is used in human health risk assessment to extrapolate from the results of animal studies and predict concentrations that will produce adverse effects in humans. This factor incorporates both toxicokinetic and toxicodynamic considerations. In the case of RfCs, dosimetric adjustments are made to experimental animal NOAELs. These dosimetric adjustments are considered less uncertain than for the RfD; thus, a factor of 3 instead of 10 is applied. In ecological risk assessment, a factor of 10 may also be used to extrapolate from results determined for a laboratory test species and predict the dose expected to cause an adverse effect in a related wildlife species.

Various empirical data have been used to develop methods to make taxonomic extrapolations about the sensitivity of various species, genera, families, orders, or functional groups to contaminants (Suter 1993). Differences between species in sensitivity to contaminants have been studied extensively for certain contaminants, such as pesticides. In general, uncertainties associated with extrapolating between orders, classes, and phyla tend to be higher than for extrapolation between species within a genus, or between genera within a family (Suter 1993; USEPA 1998a). Uncertainty factors of 10 for taxonomic variance are, in some cases, based on the finding that the lowest $\mathrm{LC}_{50}$ for a subset of test species is usually within an order of magnitude of the lowest $\mathrm{LC}_{50}$ for all test species (Suter 1993). However, given that most species have not been tested, actual differences may be greater than an order of magnitude. Therefore, the magnitude of uncertainty associated with differences between an appropriate, reasonably sensitive test species and a particular species of concern could be greater than an order of magnitude and is ranked as moderate.

Acute-to-chronic or subchronic-to-chronic. Unless the NOAEL used in determining an RfD and/or RfC is based on a chronic study, USEPA applies an uncertainty factor of 10 to account for anything less than lifetime exposures. This factor is also used in ecological risk assessment. Uncertainty associated with this extrapolation has been shown to be moderate (Kenaga 1982).

LOAEL to NOAEL. Both human health noncarcinogenic toxicity estimates and ecological toxicity reference values incorporate an uncertainty factor of 10 when extrapolating from an LOAEL to an NOAEL. Uncertainty associated with this extrapolation can be easily quantified and is expected to be low.

Although the uncertainty associated with each individual extrapolation is low to moderate, use of several uncertainty factors together could result in a significant overestimate of risk that is highly uncertain.

Timing of exposure. Exposure during sensitive life stages of either test organisms or humans can influence the type and magnitude of toxic effects. Generally, no uncertainty factor is applied to account for this potential effect. It remains as a source of uncertainty in the risk assessment. This source of uncertainty is not ranked because few data exist to measure this uncertainty across a broad spectrum of chemicals and potential adverse outcomes. It would be moderately difficult to undertake studies needed to reduce this uncertainty, assuming laboratory assays could be used rather than epidemiological investigations. 


\section{Toxic effects of mixtures}

Contaminants that exhibit similar modes of action can produce toxic effects that are synergistic or antagonistic. Assessments that examine such compounds independently could underestimate or overestimate risk. Several approaches are being developed that attempt to address this deficiency in current risk assessment methodology. Some of these approaches predict effects of mixtures based on measured or modeled body burdens of particular classes of organic contaminants. For example, narcosis theory predicts that nonpolar hydrophobic contaminants will produce a narcotic effect on exposed organisms. This effect is thought to occur when hydrophobic contaminants partition into the lipid phase of the organism, including the lipid bilayer of the cellular membrane, and cause a physical deformation or swelling or the membrane (van Wezel and Opperhuizen 1995). Acute narcosis has been demonstrated to occur in aquatic organisms at whole body concentrations of 2 to $8 \mathrm{mmol}$ total contaminant per $\mathrm{kg}$ wet weight tissue (McCarty and Mackay 1991). Because the molecular size of most nonpolar organic contaminants of concern does not vary considerably, this approach can be used to predict narcotic effects of single contaminants or the molar sum of a mixture of contaminants. Variability in the tissue concentration that produces the toxic effect (2-8 $\mathrm{mmol} / \mathrm{kg})$ is reduced when concentrations of narcotics are determined on a lipid normalized basis (van Wezel et al. 1995).

Another approach predicts the effects associated with body burdens of dioxinlike compounds (Giesy, Ludwig, and Tillitt 1994). In this approach, organic contaminants that are extracted from tissue are tested for dioxinlike activity in a sensitive in vitro bioassay. The bioassay measures the induction of cytochrome $\mathrm{P} 450$ enzyme activity in a cell line that is exposed to the tissue extract. Induction of P450 activity has been shown in this bioassay to be an indicator of exposure to dioxinlike compounds, such as some PCBs, dioxins, and furans. In some cases, bioassay activity of tissue extracts from exposed organisms has been shown to be strongly correlated with adverse reproductive effects in birds (Tillitt et al. 1992, Auman et al. 1997).

In a related approach, tissue concentrations of dioxinlike compounds that are measured by standard analytical techniques can be expressed in terms of their potency in comparison to the most potent compound, 2,3,7,8-TCDD. Standard conversion factors, called Toxic Equivalency Factors (TEF), have been established for a variety of compounds and receptors. For example, the TEF for $1,2,3,4,7,8$-hexachlorodibenzodioxin (HxCDD) in fish is 0.5 , because this compound has been shown to be half as potent as 2,3,7,8-TCDD in various bioassays and toxicity tests. Separate TEFs have been established for humans/mammals, fish, and birds on the basis of differences between taxa in their response to these compounds (World Health Organization (WHO) 1997). ${ }^{1}$ Individual compounds have different levels of uncertainty associated with their corresponding TEFs, but in general, uncertainty in the values of TEFs for individual compounds are expected to be less than an order of magnitude (Eastern Research Group (ERG) 1998).

\footnotetext{
${ }^{1}$ World Health Organization. (1997). Draft report on the meeting on the derivation of toxic equivalency factors (TEFs) for PCBs, PCDDs, PCDFs and other dioxinlike compounds for humans and wildlife. Stockholm, Sweden, 15-18 June 1977.
} 
Other empirical approaches predict the probability that mixtures of sedimentassociated contaminants will result in toxicity to benthic invertebrates. For example, the Sum-PAH model (Swartz et al. 1995) established a regression relationship between the $K_{o w}$ of individual PAHs and the concentration in sediment that results in acute toxicity to benthic invertebrates in spiked sediment bioassays (10-day $\mathrm{LC}_{50}=1$ toxic unit). The regression relationship is used to predict the $\mathrm{LC}_{50}$ of PAHs that have not been tested in bioassays. In this approach, the concentration of each PAH in a field-collected sediment is expressed as a fraction of its $\mathrm{LC}_{50}$. A large data set that contains matched information on concentration of PAHs in field-collected sediment and results of toxicity tests was used to develop a predictive relationship. The Sum-PAH approach estimates the probability that a sediment will be acutely toxic on the basis of the sum of the PAH toxic units of individual compounds. Results of the model are more uncertain for sediments with low levels of PAHs (sum of toxic units < 0.25 ), where 79 percent $(n=379)$ of the samples in the data set were predicted to be nontoxic, but only 35 percent $(n=292)$ were observed to be nontoxic.

Other empirical approaches that predict the probability of toxicity to benthic invertebrates from the concentration of chemicals in field-collected sediment show promise in their ability to screen sediments for potential toxicity of mixtures of contaminants (e.g., Long, Field, and McDonald 1998), but uncertainties remain.

\section{Physiology and biology of receptors}

The exposure of an organism to a persistent environmental contaminant, such as PCBs, can be assessed directly by measurement of body burdens of these chemicals. However, the exposure to some chemicals, such as PAHs, cannot always be assessed directly by measuring their concentration in tissue because some organisms can rapidly convert PAHs to a variety of metabolites (Melancon et al. 1992). The metabolites, which are usually more water soluble than the parent compound, are not typically detected in environmental samples by standard analytical techniques. Exposure of organisms to chemicals that are rapidly metabolized may be underestimated if only the concentration of the parent compound is examined.

The metabolites may be either more or less toxic than the parent compound. For example, some PAHs undergo biotransformation into metabolites that are mutagenic and carcinogenic (Thakker et al. 1976). The metabolites of these chemicals can accumulate to high levels, especially in some aquatic organisms (James 1989). If the metabolites are more toxic than the parent compound, inability to detect the presence of metabolites in exposed organisms may result in an underestimate of risk.

\section{Risk Characterization}

The goal of the risk characterization is to provide a quantitative estimate of potential risk. For an ecological risk assessment, risk estimates for each chemical 
and receptor are commonly expressed as hazard quotients. The quotient method uses the ratio of a measurement end point to a toxicity reference value (e.g., NOAEL) as an approximate index of risk. Hazard quotients (HQ) are defined as:

$$
H Q=\left(C_{B} / C_{T}\right)
$$

where

$$
\begin{aligned}
C_{B}= & \text { estimated body burden ( } \mathrm{mg} \text { COC } / \mathrm{kg} \text { tissue) or dietary dose }(\mathrm{mg} \\
& \mathrm{COC} / \mathrm{kg} \text { tissue } / \text { day) to receptors of concern } \\
C_{T}= & \text { toxicity end point, expressed as body burden }(\mathrm{mg} / \mathrm{kg}) \text { or dietary } \\
& \text { dose }(\mathrm{mg} / \mathrm{kg} / \mathrm{day})
\end{aligned}
$$

For ecological risk assessments, a hazard quotient of less than 1 indicates that exposure to a particular COC is not likely to be associated with an adverse effect. Because of the uncertainties involved in the risk estimates, hazard quotients greater than 1 indicate varying levels of concern.

A number of limitations restrict the utility of the quotient method. For example, the method does not convey the potential for effects beyond those predicted by the simple quotient method (e.g., loss of prey species, biomagnification at higher trophic levels).

\section{Estimation of population-level effects from effects on individuals}

In most assessments of the effect of contaminants on biota, there is a disparity between the types of data available and the types of data needed to assess population-level effects. Most toxicological data are obtained from short-term toxicity tests on standard laboratory species. However, the effects of greatest concern in ecological risk assessments are those resulting from long-term exposures on the persistence, abundance, and/or production of populations (Barnthouse et al. 1987). Unfortunately, data on population-level effects of contaminants are sparse, and population-level effects are difficult to predict. In some cases, effects on individuals may not be intense enough to be observed at the level of the population. In other cases, effects on individuals may occur, but compensatory mechanisms (e.g., increased migration into an area) may preclude the occurrence of population- or community-level effects. Alternatively, longterm community-level changes may occur that are not predicted on the basis of short-term toxicity tests (Swartz et al. 1994).

In some cases, sufficient data may be available to develop a dose-response function for population-level effects, such as the reproductive potential of female fish (Barnthouse et al. 1987), or increased mortality of offspring (Moore, Breton, and Lloyd 1997). Because prediction of community-level responses from survival, growth, and reproductive end points involves substantial uncertainties, wherever practical, effects on selected communities should be directly observed in the field (USEPA 1993c). 


\section{Joint distributional analysis}

In this approach, exposure concentrations and effects concentrations are expressed as distributions. Predicted exposure values are compared to a distribution of toxicity effects obtained from the literature or from site-specific information. The overlap in the two distributions can be used to estimate risk (Suter 1993; USAEWES 1992).

Developing such a model includes the following steps:

a. Define the assessment end point (e.g., the probability of reproductive failure in a particular fish species) in terms of a test end point (e.g., the probability of exceeding a relevant effects end point).

b. Obtain the relevant data (i.e., effects data and exposure concentration data).

c. Calculate the risk that the expected distribution of environmental concentrations will exceed the distribution of effects concentrations.

This kind of model can be combined with a logistic or binomial model to evaluate the potential for risk at the population level. However, the appropriate level of protection must be selected, which is a risk management decision.

\section{Temporal considerations: Potential for recovery of populations}

In ecological risk assessments it is desirable to consider how long an ecosystem may remain degraded after some assault (Suter 1993). Population levels of some species may recover almost immediately after exposure ceases. Other species might require longer recovery periods before pre-exposure population levels are restored. For example, Kennelly (1987) demonstrated that the removal of adult kelp plants has little effect if it occurs during the time of year when the plants are reproducing. If, however, plants are removed at other times of the year, other species may occupy the space and substantially delay the return of the kelp. Currently, it is not possible to predict the duration of effects accurately, since the timing, magnitude and order of stresses can cause unpredictable effects on populations and complicate interpretations of patterns of competition and predation (Underwood 1989). 


\section{Preliminary Ranking and Recommendations}

Table 4 lists the preliminary ranking scores for uncertainty sources in the tiered evaluation of dredged material. These scores should be viewed as initial estimates of the relative amount of uncertainty associated with each source.

Scores ranged from 1 to 6 . A source of uncertainty considered in the tiered evaluation process and ranked low in magnitude received a score of 1. A source of uncertainty for which the tiered evaluation process offers no explicit guidance and which is ranked high in magnitude received a score of 6 . A relatively small subset of sources received a score of 3 or higher, and these sources are described in the following paragraphs. Efforts to describe and reduce uncertainty in dredged material disposal decisions should begin with these sources. Sources that were not ranked (NR), classified as model-specific (MS), or classified as projectspecific (PS) were not scored, although they might be important. It is beyond the scope of this report to quantify their importance. The following sections describe sources of uncertainty, scored or unscored, that are good candidates for further analysis.

\section{COC Characterization}

Identification of COCs received a score of 3 because some COCs might not be evaluated at all in the tiered process. For example, contaminants that may have potential endocrine-disrupting effects are not considered explicitly in USACE guidance, although potential COC lists include some of these compounds.

\section{Selection of Reference Sediment}

Selection of reference sediments was not scored because, while applicable USACE guidance is appropriate and thorough, uncertainty associated with poor application of this guidance could not be quantified. However, it is clear that this source of uncertainty deserves attention because the selection of reference sediments is central to decisions made at every tier. 


\begin{tabular}{|c|c|}
\hline \multicolumn{2}{|l|}{$\begin{array}{l}\text { Table } 4 \\
\text { Preliminary Ranking of Sources of Uncertainty }\end{array}$} \\
\hline Uncertainty Source & Preliminary Ranking \\
\hline \multicolumn{2}{|c|}{ Tier I Evaluation } \\
\hline $\begin{array}{l}\text { Identification of COCs } \\
\text { Sampling uncertainty } \\
\text { Spatial representativeness } \\
\text { Analytical uncertainty } \\
\text { Dredged material physical and chemical characteristics } \\
\text { Description of dredging and disposal activities including quantity of material to be dredged } \\
\text { Selection of reference sediment }\end{array}$ & $\begin{array}{l}3 \\
1 \\
1 \\
1 \\
1 \\
1 \\
\text { NR }\end{array}$ \\
\hline \multicolumn{2}{|c|}{ Tier II Evaluation } \\
\hline $\begin{array}{l}\text { Water Column Impact } \\
\text { Numerical mixing models } \\
\text { Benthic Impact } \\
\text { Theoretical bioaccumulation potential for nonpolar organics } \\
\text { Equilibrium sediment guidelines }\end{array}$ & $\begin{array}{l}2 \\
2 \\
2\end{array}$ \\
\hline \multicolumn{2}{|c|}{ Tier III Evaluation } \\
\hline $\begin{array}{l}\text { Water Column Bioassay } \\
\text { Precision of bioassay } \\
\text { Interpretation of bioassay } \\
\text { Sediment Bioassay } \\
\text { Precision of bioassay } \\
\text { Interpretation of bioassay } \\
\text { Benthic Bioaccumulation } \\
\text { Bioavailability from sediments } \\
\text { Trophic transfer } \\
\text { Fish } \\
\text { Piscivorous birds }\end{array}$ & $\begin{array}{l}1 \\
2 \\
1 \\
2 \\
2 \\
3 \\
3\end{array}$ \\
\hline \multicolumn{2}{|c|}{ Tier IV Evaluation: Chronic Bioassays } \\
\hline $\begin{array}{l}\text { Chronic Bioassays } \\
\text { Precision of bioassay } \\
\text { Interpretation of bioassay }\end{array}$ & $\begin{array}{l}1 \\
5\end{array}$ \\
\hline & (Sheet \\
\hline
\end{tabular}




\section{Table 4 (Continued)}

Uncertainty Source

Preliminary Ranking

Tier IV: Human Health and Ecological Risk Assessments Problem Formulation/Hazard Identification

Characterization of Dredged Material - see Tier I

Development of Conceptual Model

Characterization of the surrounding environment

Identification of complete and incomplete pathways

Selection of potential receptors

Assessment and Measurement End Points

Selecting assessment end points

Selecting measurement end points

NR
PS
PS
NR
PS

Exposure Assessment

Estimation of Exposure Point Concentrations

Fate and transport models: model uncertainty

Fate and transport models: parameter uncertainty

Physical and chemical properties of COCs $\left(\mathrm{K}_{\mathrm{ow}}, \mathrm{K}_{\mathrm{oc}}, \mathrm{K}_{\mathrm{doc}}\right)$

Physical and chemical properties of COCs (vapor pressure, molecular weight, solubility)

Bioaccumulation of COCs

Bioavailability from sediments for ecological receptors

Bioavailability from water for ecological receptors

Exposure models for aquatic organisms: equilibrium models

Use of equilibrium models when time-variant models are more appropriate

Parameter uncertainty (uptake, elimination, and growth rates, etc.)

Exposure models for semiaquatic organisms and humans: model uncertainty

Exposure models for semiaquatic organisms and humans: parameter uncertainty

Physiological characteristics (e.g., body weight, inhalation rate, etc.)

Exposure duration (migration, foraging area, feeding patterns)

Time-activity patterns for workers involved in dredging and disposal activities

MS

2 


\section{Table 4 (Concluded)}

Uncertainty Source

Preliminary Ranking

Effects Assessment

Toxicity end points for ecological receptors

Toxicity end points based on body burdens

Toxicity end points for human receptors

Dose-response models for carcinogens and noncarcinogens

Extrapolation

Intraindividual/intraspecies

Interindividual/interspecies

Exposure period extrapolation

LOAEL to NOAEL

Timing of exposure (e.g., exposure during sensitive life stages)

Toxicity of complex mixtures of COC (synergism, antogonism)

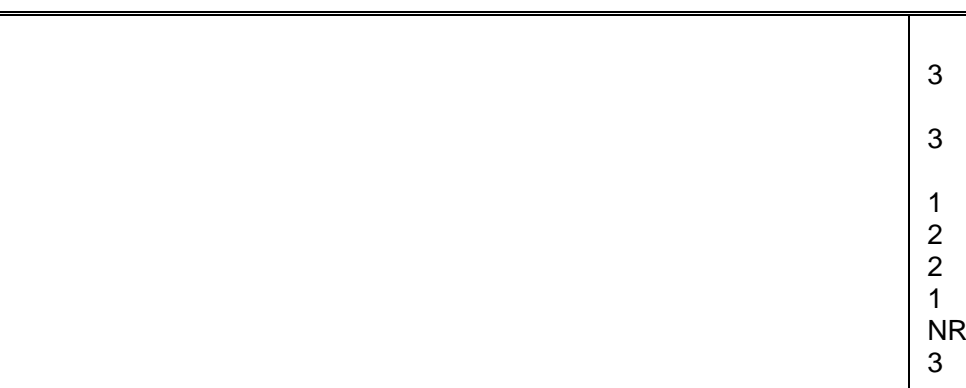

Hazard/toxicity quotient approach

Potential for recovery of populations

Estimation of population-level effects

Risk Characterization

(Sheet 3 of 3 ) 


\section{Trophic Transfer}

Trophic transfer received a score of 3 . This score includes 3 points to reflect the high ranking for magnitude of uncertainty. In Tier III, if dredged material bioaccumulation significantly exceeds bioaccumulation in the reference sediment, the biomagnification potential of COCs must be considered. However, no guidance explains how to evaluate this potential impact quantitatively.

\section{Chronic Bioassays}

Chronic bioassays received a score of 5 , with 2 points for a moderate ranking for magnitude of uncertainty and 3 points for not accounting for population-level effects. Although prediction of the environmental impact on the basis of results of laboratory bioassays is uncertain, chronic bioassay results can be used in conjunction with demographic models to evaluate the potential for long-term impacts on populations. Use of quantitative uncertainty analysis and probabilistic modeling will be critical elements in such an approach.

\section{Assessment and Measurement End Points}

Assessment end points and measurement end points were not scored. Like many other elements of the "Problem Formulation" step in risk assessments, selection of these end points is primarily a qualitative step. However, there is significant uncertainty in selecting appropriate assessment and measurement end points. Often, it is the relationship (or lack thereof) between the assessment and measurement end points that dominates the uncertainty. An explicit protocol for selection of appropriate measurement and assessment end points with an emphasis on a clear connection between the two would reduce the uncertainty associated with selecting ill-defined measurement and assessment end points.

\section{Fate and Transport Models}

To support risk assessments, fate and transport models are needed to provide estimates of contaminant concentrations at locations where humans and ecological receptors might contact dredged material contaminants. These models received no score in this report because many models are available, each with varying degrees of associated uncertainty. 


\section{Toxicity End Points Based on Body Burdens for Ecological Receptors}

Toxicity end points based on body burdens for ecological receptors received a score of 3 for high magnitude of uncertainty. Data are available for nonpolar organics, but fewer data are available for metals.

The relationship between toxicity end points and body burdens is complicated when the contaminant is metabolized by the organism. Some organisms can metabolize contaminants to more or less toxic forms, but prediction of how a particular chemical will be metabolized by a particular organism is difficult. Also, since most metabolites are not detected by conventional analytical methods, exposure of animals may be underestimated.

\section{Dose-Response Models for Human Receptors}

Dose-response models for human receptors received a score of 3 for high magnitude of uncertainty. This uncertainty encompasses both the shape of the dose-response curve as well as the uncertainties encountered when extrapolating from animal to human studies. A national scientific commission recently reviewed problems associated with such extrapolations (Presidential/ Congressional Commission on Risk Assessment and Risk Management 1997). To extrapolate from animal toxicity data to an "acceptable" concentration or dose in humans, USEPA applies uncertainty factors that range from 10 to 10,000. The Presidential/Congressional Commission on Risk Assessment and Risk Management made practical recommendations for future animal studies to minimize these uncertainties.

\section{Toxicity of Complex Mixtures}

The toxicity of complex mixtures is not well understood for humans or ecological receptors. Approaches are being developed to address this uncertainty (Swartz et al. 1995; van Wezel and Opperhuizen 1995; and Giesy, Ludwig, and Tillitt 1994) and should be pursued within the dredged material management program. Prediction of human health impacts from chemical mixtures is equally if not more problematic, because there is such a small database for chemical mixture toxicity data for such mixtures as tobacco smoke and diesel exhaust. Alternatively, researchers often must rely on models (e.g., toxicity equivalency factors for dioxinlike compounds). To enlarge the toxicity database for chemical mixtures, coordinated research efforts are needed among epidemiologists and toxicologists. 


\section{The Need for Field Validation}

Field validation projects would help USACE to understand whether predictions of fate and transport models, bioaccumulation models, and toxicity tests are relevant to field conditions. Uncertainties could be reduced through a series of small, strongly focused field validation efforts that target dominant elements of the dredged material evaluation process (e.g., use and reliability of chronic sublethal bioassays, bioaccumulation and trophic transfer modeling, population modeling). Such field validation could be performed in conjunction with population modeling efforts to improve understanding of any dredged material impacts and to test model predictions.

It would also be useful to learn from past USACE experience by reviewing a carefully selected subset of toxicity and bioaccumulation bioassay data. For example, data submitted in support of permit applications could provide a useful starting point for evaluating the potential for trophic transfer of nonpolar organic contaminants. Trophic transfer can be evaluated by using sediment concentration data and sediment characteristics information (e.g., organic carbon content) in a trophic transfer model such as Gobas (1993) or FGETS (Barber, Suárez, and Lassiter 1988 and 1991). Predicted concentrations from the model(s) can be used to evaluate whether the potential for trophic transfer occurs at sites for which disposal was deemed acceptable. Toxicity testing results could be analyzed to validate the $\Sigma$ PAH model (Swartz et al. 1995). Results from such data analyses could benefit the development of bioassay interpretation guidance for USACE field staff.

A well-conceived plan coordinating data analysis, modeling, and field monitoring efforts is needed to ensure that principal sources of uncertainty in the dredged material tiered evaluation are reduced. 


\section{References}

Ankley, G. T., Call, D. J., Cox, J. S., Kahl, M. D., Hoke, R. A., and Kosian, P. A. (1994). "Organic carbon partitioning as a basis for predicting the toxicity of chlorpyrifos in sediments," Environ. Toxicol. Chem. 13, 621-626.

Auman, H. J., Ludwig, J. P., Summers, C. L., Vergrugge, D. A., Froese, K. L., Colburn, T., and Giesy, J. P. (1997). "PCBs, DDE, DDT and TCDD-EQ in two species of albatross on Sand Island, Midway Atoll, North Pacific Ocean," Environ. Toxicol. Chem. 16, 498-504.

Barber, M. C., Suárez, L. A., and Lassiter, R. R. (1988). "Modeling bioconcentration of nonpolar organic pollutants by fish," Environ. Toxicol. Chem. 7, 545-558.

Barber, M. C., Suárez, L. A., and Lassiter, R. R. (1991). "Modeling bioaccumulation of organic pollutants in fish with an application to PCBs in the Great Lakes salmonids,"Can. J. Fish. Aquat. Sci. 48, 318-337.

Barnthouse, L. W., Suter, G. W., II, and Rosen, A. E. (1989). "Inferring population-level significance from individual-level effects: An extrapolation from fisheries science to ecotoxicology," Aquatic toxicology and environmental fate: Eleventh Volume, ASTM STP 1007, G. W. Suter II and M. A. Lewis, eds., American Society for Testing and Materials, Philadelphia, 289-300.

Barnthouse, L. W., Suter, G. W., II, and Rosen, A. E. (1990). "Risks of toxic contaminants to exploited fish populations: Influence of life history, data uncertainty and exploitation intensity," Environ. Toxicol. Chem. 9, 297-311.

Barnthouse, L. W., Suter, G. W., II, Rosen, A. E., and Beauchamp, J. J. (1987). "Estimating responses of fish populations to toxic contaminants," Environ. Toxicol. Chem. 6, 811-824.

Bogen, K. T., and Spear, R. C. (1987). "Integrating uncertainty and interindividual variability in environmental risk assessment," Risk Analysis 7, 427-436.

Box, G. E. P., and Tiao, G. C. (1973). Bayesian inference in statistical inference. Wiley \& Sons, New York. 
Bridges, T. S., and Farrar, J. D. (1997). "The influence of worm age, duration of exposure and end point selection on bioassay sensitivity for Neanthes arenaceodentata (Annelida: Polychaeta)," Environ. Toxicol. Chem. 16, 16501658.

Bridges, T. S., Farrar, J. D., and Duke, B. M. (1997). "The influence of food ration on sediment toxicity in Neanthes arenaceodentata (Annelida: Polychaeta)," Environ. Toxicol. Chem. 16, 1659-1665.

Brownawell, B. J., and Farrington, J. W. (1986). "Biogeochemistry of PCBs in interstitial waters of a coastal marine sediment," Geochim. Cosmochim. Acta 50, 157-169.

Burkhard, L. P. (1998). "Comparison of two models for predicting bioaccumulation of hydrophobic organic chemicals in a Great Lakes food web, Environ. Toxicol. Chem. 17, 383-393.

Burmaster, D. E., and Wilson, A. E. (1996). "An introduction to second-order random variables in human health risk assessments," Human Ecol. Risk Assess. 2(4), 892-919.

Burmaster, D. E., and von Stackelberg, K. (1991). "Using Monte Carlo simulations in public health risk assessments: Estimating and presenting full distributions of risk," Journal Exp. Anal. Environ. Epidemiol. 1, 491-512.

Burton, G. A., Jr., Norberg-King, T. J., Ingersoll, C. G., Benoit, D. A., Ankley, G. T., Winger, P. V., Kubitz, J., Lazorchak, J. M., Smith, M. E., Greer, E., Dwyer, F. J., Call, D. J., Day, K. E., Kennedy, P., and Stinson, M. (1996). "Interlaboratory study of precision: Hyallella azteca and Chironomus tentans freshwater sediment toxicity assays," Environ. Toxicol. Chem. 15, 1335-1343.

Cerniglia, C. E., and Heitkamp, M. A. (1989). "Microbial degradation of polycyclic aromatic hydrocarbons (PAH) in the aquatic environment." Metabolism of polycyclic aromatic hydrocarbons in the aquatic environment. U. Varanasi, ed., CRC Press, Boca Raton, FL, 41-68.

Cooke, R. M. (1991). Experts in uncertainty opinion and subjective problems in science. Oxford University Press, New York.

DiToro, D. M., Zarba, C. S., Hansen, D. J., Berry, W. J., Swartz, R. C., Cowan, C. E., Pavlou, S. P., Allen, H. E., Thomas, N. A., and Paquin, P. R. (1991). "Technical basis for establishing sediment quality criteria for nonionic organic chemicals using equilibrium partitioning." Environ. Toxicol. Chem. $10,1541-1583$.

Dourson, M. L., and Stara, J. F. (1983). "Regulatory history and experimental support of uncertainty (safety) factors," Reg. Toxicol. Pharm. 3, 224-238. 
Eastern Research Group. (1998). Report from the Workshop on the Application of 2,3, 7,8-TCDD Toxicity Equivalency Factors to Fish and Wildlife, Chicago, IL, January 20-22, 1998. Published on microfiche by U.S. Government Printing Office, Washington, DC.

Evans, J. S., Gray, G. M., Sielken, R. L., Smith, A. E., Valdez-Flores, C., and Graham, J. D. (1994). "Use of probabilistic expert judgment in uncertainty analysis of carcinogenic potency," Regul. Toxicol. Pharmacol. 20, 15-36.

Ferson, S. (1991). "RAMAS/stage: Generalized stage-based modeling for population dynamics," Applied Biomathematics, Setauket, NY.

Ferson, S., and Burgman, M. (1995). "Correlations, dependency bounds and extinction risks," Biological Conservation 73, 101-105.

Ferson, S., and Kuhn, R. (1992). "Propagating uncertainty in ecological risk analysis using interval and fuzzy arithmetic. Computer techniques in environmental studies IV. P. Zannetti, ed., Elsevier Applied Science, London, 387-401.

Ferson, S., and Long, T. F. (1995). "Conservative uncertainty propagation in environmental risk assessment." Environmental toxicology and risk assessment: Third Volume. ASTM STP 1218, J. S. Hughes, G. R. Biddinger, and E. Mones, eds., American Society for Testing and Materials, Philadelphia, 97-110.

Frey, C. (1992). "Quantitative analysis of uncertainty and variability in environmental policy making." Center for Energy and Environmental Studies, Department of Engineering and Public Policy, Carnegie Mellon University, Pittsburgh, PA.

Gelman, A., Carlin, J. B., Stern, H. S., and Rubin, D. B. (1995). Bayesian data analysis. Chapman \& Hall, London.

Giesy, J. P., Ludwig, J. P., and Tillitt, D. E. (1994). "Deformities on birds of the Great Lakes region: Assigning causality," Environ. Sci. Technol. 28, 128A135A.

Gobas, F. P. C. (1993). "A model for predicting the bioaccumulation of hydrophobic organic chemicals in aquatic food webs: Application to Lake Ontario," Ecolog. Monogr. 69, 1-17.

Graham, J. D., Hawkins, N. C., and Roberts, M. J. (1988). "Expert scientific judgment in quantitative risk assessment." Carcinogen risk assessment: New directions in the qualitative and quantitative aspects. Banbury Report 31, Cold Spring Harbor Laboratory, Cold Spring Harbor, NY, 231-244.

Gustafsson, O., Haghseta, F., Chan, C., MacFarlane, J., and Gschwend, P. M. (1997). "Quantification of the dilute sedimentary soot phase: Implications for PAH speciation and bioavailability," Environ. Sci. Technol. 31, 203-209. 
Hattis, D., and Goble, R. L. (1994). "Current priority-setting methodology: too little rationality or too much?" Worst things first? The debate over risk-based national environmental priorities. A. M. Finkel and D. Golding, eds., Resources for the Future, Washington, DC, Chapter 7.

Hawker, D. W., and Connell, D. W. (1988). "Octanol-water partition coefficients of polychlorinated biphenyl congeners," Environ. Sci. Technol. 22, 382-387.

Herbes, S. E., and Schwall, L. R. (1978). "Microbial transformation of polycyclic aromatic hydrocarbons in pristine and petroleum-contamianted sediments," Appl. Environ. Microbiol. 35, 306-316.

Hoke, R. A., Kosian, P. A., Ankley, G. T., Cotter, A. M., Vandermeiden, F. M., Phipps, G. L., and Durhan, E. J. (1995). "Check studies with Hyalella azteca and Chrominomus tentans in support of the development of a sediment quality criterion for dieldrin," Environ. Toxicol. Chem. 14, 435-443.

Iannuzzi, T. J., Harrington, N. W., Shear, N. M., Curry, C. L., Carlson-Lynch, H., Henning, M. H., Su, S. H., and Rabbe, D. E. (1996). "Distributions of key exposure factors controlling the uptake of xenobiotic chemicals in an estuarine food web," Environ. Toxicol. Chem. 15, 1979-1992.

Ingersoll, C. G., Ankley, G. T., Baudo, R., Burton, G. A., Lick, W., Luoma, S. N., MacDonald, D. D., Reynoldson, T. B., Solomon, K. R., Swartz, R. C., and Warren-Hicks, W. J. (1997). "Workgroup summary report on uncertainty evaluation of measurement end points used in sediment ecological risk assessment. Ecological risk assessment of contaminated sediments, Society of Environmental Toxicology and Chemistry Press, Pensacola, FL, 297-352.

James, M. O. (1989). "Biotransformation and disposition of aromatic hydrocarbons in aquatic invertebrates." Metabolism of polycyclic aromatic hydrocarbons in aquatic invertebrates. U. Varanasi, ed., CRC Press, Boca Raton, FL, 69-92.

Jones, P. D., Ankley, G. T., Best, D. A., Crawford, R., DeGalan, N., Giesy, J. P., Kubiak, T. J., Ludwig, J. P., Newsted, J. L., Tillitt, D. E., and Verbrugge, D. A. (1993). "Biomagnification of bioassay derived 2,3,7,8tetrachlorodibenzo-p-dioxin equivalents," Chemosphere 26, 1203-1212.

Kane Driscoll, S. B., Harkey, G. A., and Landrum, P. F. (1997). “Accumulation and toxicokinetics of fluoranthene in sediment bioassays with freshwater amphipods," Environ. Toxicol. Chem. 16, 742-753.

Kane Driscoll, S. B., Schaffner, L. C., and Dickhut, R. M. (1998). "Toxicokinetics of fluoranthene to the amphipod, Lepotcheirus plumulosus, in water-only and sediment exposures, Mar. Environ. Res. 45, 269-284.

Keith, L. H., Crummett, W., Deegan, J., Jr., Libby, R. A., Taylor, J. K., and Wentler, G. (1983). "Principles of environmental analysis," Anal. Chem. 55, 2210-2218. 
Kenaga, E. E. (1982). "Predictability of chronic toxicity from acute toxicity of chemicals in fish and aquatic invertebrates," Environ. Toxicol. Chem. 1, 347358.

Kendall, R., Dickerson, R., Giesy, J., and Suk, W. (1995). Principles and processes for evaluating endocrine disruption in wildlife. Society of Environmental Toxicology and Chemistry Press, Pensacola, FL.

Kennelly, S. J. (1987). "Physical distrubances in an Australian kelp community: Temporal effects," Mar. Ecol. Progr. Ser. 40, 145-153.

Kidd, K. A., Schindler, D. W., Muir, D. C. G., Lockhart, W. L., and Hesslein, R. H. (1995). "High concentrations of toxaphene in fishes from a subartic lake," Science 269, 240-242.

Kuhn, A., Munns, W., Champlin, D., McKinney, R., Serbst, J., Tagliabue, M. and Gleason, T. (1997a). "Evaluation of the efficacy of extrapolation population modeling to predict the dynamics of Mysidopsis bahia populations in the laboratory" (Abstract). Society of Environmental Toxicology and Chemistry $18^{\text {th }}$ Annual Meeting, San Francisco, CA, November 16-20, 1997. Society of Environmental Toxicology and Chemistry, Pensacola, FL.

Kuhn, A., Serbst, J., Pelletier, M., Rego, S., and Munns, W. (1997b). "Baseline field demographic data for a population of the estuarine amphipod Ampelisca abdita" (Abstract). Society of Environmental Toxicology and Chemistry $18^{\text {th }}$ Annual Meeting, San Francisco, CA, November 16-20, 1997. Society of Environmental Toxicology and Chemistry, Pensacola, FL.

Landrum, P. F., Nihart, S. R., Eadie, B. J., and Gardner, W. S. (1984). "Reversephase separation method for determining pollutant binding to Aldrich humic acid and dissolved organic carbon of natural waters," Environ. Sci. Technol. 18, 187-192.

Landrum, P. F., Fontaine, T. D., Faust, W. R., Eadie, B. J., and Lang, G. A. (1985). "Predicting the bioavailability of organic xenobiotics to Pontoporeia hoyi in the presence of humic and fulvic materials and natural dissolved organic carbon," Environ. Toxicol. Chem. 4, 459-467.

Landrum, P. F., Nihart, S. R., Eadie, B. J., and Herche, L. R. (1987). "Reduction in bioavailability of organic contaminants to the amphipod Pontoporeia hoyi by dissolved organic matter of sediment interstitial waters," Environ. Toxicol. Chem. 6, 11-20.

Long, E. R., Field, J. L., and MacDonald, D. D. (1998). "Predicting toxicity in marine sediments with numerical sediment quality guidelines," Environ. Toxicol. Chem. 17, 714-727.

Ludwig, J. P., Auman, H. J., Kurita, H., Ludwig, M. E., Campbell, L. M., Giesy, J. P., Tillitt, D. E., Jones, P., Yamashita, N., Tanabe, S., Tatsukawa, R. (1993). "Caspian tern reproduction in the Saginaw Bay ecosystem following a 100-year flood event," J. Great Lakes Res. 19, 96-108. 
Mackay, D., Shiu, W. Y., and Ma, K. C. (1992a). Illustrated handbook of physical-chemical properties and environmental fate for organic chemicals; Volume I: Monoaromatic hydrocarbons, chlorobenzenes, and PCBs. Lewis Publishers, Boca Raton, FL.

Mackay, D., Shiu, W. Y., and Ma, K. C. (1992b). Illustrated handbook of physical-chemical properties and environmental fate for organic chemicals; Volume II: Polynuclear aromatic hydrocarbons, polychlorinated dioxins, and dibenzofurans. Lewis Publishers, Boca Raton, FL.

Maugh, T. H. (1978). “Chemicals: How many are there?” Science 199, 162.

McCarthy, J. F., and Jimenez, B. D. (1985). "Reduction in bioavailability to bluegills of polycyclic aromatic hydrocarbons bound to dissolved humic material," Environ. Toxicol. Chem. 4, 511-521.

McCarthy, J. F., Jimenez, B. D., and Barber, T. (1985). "Effects of dissolved humic material on accumulation of polycyclic aromatic hydrocarbons: structure-activity relationships," Aquat. Toxicol. 7, 15-24.

McCarty, L. S., and Mackay, D. (1991). "Enhancing ecotoxicological modeling and assessment," Environ. Sci. Technol. 27, 1719-1728.

McFarland, V. F. (1984). "Activity-based evaluation of potential bioaccumulation from sediments." Dredging and dredged material disposal: Proceedings of the Conference Dredging '84, Clearwater Beach, FL, November 14-16, 1984. Raymond L. Montgomery and Lamie W. Leach, eds. American Society of Civil Engineers, New York, 1, 461-467.

McGee, B. L., Schlekat, C. E., and Reinharz, E. (1993). "Assessing sublethal levels of sediment contamination using the estuarine amphipod Leptocheirus plumulosus," Environmental Toxicol. Chem. 12, 577-587.

McGroddy and Farrington. (1995). "Sediment and porewater partitioning of polycyclic aromatic hydrocarbons in three cores from Boston Harbor, Massachusetts," Environ. Sci. Technol. 29, 1542-1550.

McKone, T. E., and Bogen, K. T. (1992). "Uncertainties in health risk assessment: An integrated case based on tetrachloroethylene in California groundwater," Reg. Tox. Pharm. 15, 86-103.

Melancon, M. J., Alscher, R., Benson, W., Kruzynski, G., Lee, R. F., Sikka, H. C., and Spies, R. B. (1992). "Metabolic products of biomarkers." Biomarkers: Biochemical, physiological and histological markers of anthropogenic stress. R. Huggett, R. A. Kimerle, P. M. Mehrle, and N. L. Bergmen, eds., Lewis Publishers, Chelsea, MI, 87-123.

Meyer, J. S., Ingersoll, C. G., McDonald, L. L., and Boyce, M. S. (1986). "Estimating uncertainty in population growth rates: Jacknife vs. Bootstrap techniques," Ecology 67, 1156-1166. 
Moore, D. W., and Dillon, T. M. (1993). "The relationship between growth and reproduction in the marine polychaete Nereis (Neanthes) arenaceodentata (Moore): Implications for chronic sublethal sediment bioassays," J. Exp. Mar. Biol. Ecol. 173, 231-246.

Moore, D. R. J., Breton, R. L., and Lloyd, K. (1997). "The effects of hexachlorobenzene on mink in the Canadian environment: An ecological risk assessment, Environ. Toxicol. Chem. 16, 1042-1050.

Moore, D. W., Bridges, T. S., Gray, B. R., and Duke, B. M. (1996). "Risk of ammonia toxicity during sediment bioassays with the estuarine amphipod Leptocheirus plumulosus," Environ. Toxicol. Chem. 16, 1020-1027.

Morgan, M. G. (1994). "Quantitative risk ranking: More promise than the critics suggest." Worst things first? The debate over risk-based national environmental priorities. A. M. Finkel and D. Golding, eds., Resources for the Future, Washington, DC, Chapter 8.

Morgan, M. G., and Henrion, M. (1990). Uncertainty: A guide to dealing with uncertainty in quantitative risk and policy analysis. Cambridge University Press, New York.

Mudroch, A., and Azcue, J. M. (1995). Manual of aquatic sediment sampling. $1^{\text {st }}$ ed., Lewis Publishers, Boca Raton, FL.

Nacci, D., Coiro, L., Champlin, D., Pelletier, M., Gleason, T., Munns, W. R., and Cooper, K. (1997). "Persistence of estuarine fish populations at a marine superfund site" (Abstract). Society of Environmental Toxicology and Chemistry, $18^{\text {th }}$ Annual Meeting, San Francisco, CA, November 16-20, 1997.

National Council on Radiation Protection and Measurements. (1996). "A guide for uncertainty analysis in dose and risk assessments related to environmental contamination." Commentary No. 14, Bethesda, MD.

Nebert, D. W., Nelson, D. R., and Feyereisen, R. (1989). "Evolution of the cytochrome P450 genes," Xenobiotica 19, 1149-1160.

Odum, E. P. (1971). Fundamentals of ecology. W. B. Saunders, Philadelphia.

Oliver, B. G., and Niimi, A. J. (1988). "Trophodynamic analysis of polychlorinated biphenyl congeners and other chlorinated hydrocarbons in the Lake Ontario ecosystem," Environ. Sci. Technol. 22, 388-397.

Opresko, D. M., Sample, B. E., and Suter, G. W. (1994). "Toxicological benchmarks for wildlife: 1994 revision," ES/ER/TM-86/R1, Health Research Division and Environmental Sciences Division, Oak Ridge National Laboratory, Oak Ridge, TN. 
Parkhurst, D. F. (1990). "Statistical hypothesis tests and statistical power in pure and applied science." Acting under uncertainty: Multidisciplinary

conceptions. G. M. von Furstenberg, ed., Kluwer Academic Publishers, Boston, MA, 181-201.

Presidential/Congressional Commission on Risk Assessment and Risk Management. (1997). "Risk assessment and risk management in regulatory decision-making," Final Report, Volume 2.

http://www.riskworld.com/Nreports/1996/risk_rpt/Rr6me001.htm.

Rubinstein, N. I., Lake, J. L., Pruell, R. J., Lee, H., II, Taplin, B., Helshe, J., Bowen, R., and Pavignano, S. (1987). "Predicting bioaccumulation of sediment-associated organic contaminants: Development of a regulatory tool for dredged material evaluation," Technical Report D-87 prepared by the U.S. Environmental Protection Agency, Narragansett, RI, for the U.S. Army Engineer Waterways Experiment Station, Vicksburg, MS. 59 pp.

Sample, B. E., Opresko, D. M., and Suter, G. W. (1996). "Toxicological benchmarks for wildlife: 1996 revision," ES/ER/TM-86/R3, Health Sciences Research Division, Oak Ridge National Laboratory, Oak Ridge, TN.

Scott, P. K., and Trowbridge, K. R. (1995). "Screening-level versus refined modeling approaches to estimating PCB concentrations in aquatic food webs: A case study of Lake Ontario." Environmental toxicology and risk assessment: Third Volume. ASTM STP 1218, J. S. Hughes, G. R. Biddinger, and E. Mones, eds., American Society for Testing and Materials, Philadelphia, 111-132.

Shiaris, M. P. (1989). "Seasonal biotransformation of naphthalene, phenanthrene, and benzo[a]pyrene in surficial sediments," Appl. Environ. Microbiol. 55, 1391-1399.

Suter, G. L. (1993). Ecological Risk Assessment. Lewis Publishers, Boca Raton, FL.

Suter, G. L., Barnthouse, L., and Bartell, S. (1992). Ecological Risk Assessment. Lewis Publishers, Boca Raton, FL.

Swackhamer, D. L., and Skoglund, R. S. (1993). "Bioaccumulation of PCBs by algae: Kinetics versus equilibrium,” Environ. Toxicol. Chem. 12, 831-838.

Swartz, R. C., Cole, F. A., Lamberson, J. O., Ferraro, S. P., Schults, D. W., DeBen, W. A., Lee, H., II, and Ozretich, R. (1994). "Sediment toxicity, contamination and amphipod abundance at a DDT- and dieldrin-contaminated site in San Francisco Bay," Environ. Toxicol. Chem. 13, 949-962.

Swartz, R. C., Schults, D. W., Ozretich, R. J., Lamberson, J. O., Cole, F. A., DeWitt, T. H., Redmond, M., and Ferraro, S. P. (1995). "PAH: A model to predict the toxicity of polynuclear aromatic hydrocarbon mixtures in fieldcollected sediments," Environ. Toxicol. Chem. 14, 1977-1995. 
Thakker, D. R., Yagi, H., Lu, A. Y. H., Levin, W., Conney, A. H., and Jerina, D. M. (1976). "Metabolism of benzo[a]pyrene: conversion of ( \pm )-trans-7,8dihydroxy-7,8-dihydrobenzo[a]pyrene to highly mutagenic 7,8-diol-9,10epoxides," Proc. Natl. Acad. Sci. 73, 3381-3385.

Thomann, R. B. (1989). "Bioaccumulation model of organic chemical distribution in aquatic food chains," Environ. Sci. Technol. 23, 699-707.

Thomann, R. V., Connolly, J. P., and Parkerton, T. F. (1992). “An equilibrium model of organic chemical accumulation in aquatic food webs with sediment interaction," Environ. Toxicol. Chem. 11, 615-629.

Thompson, K. M., and Evans, J. S. (1997). "The value of improved national exposure information for perchloroethylene (PERC): A case study for dry cleaners," Risk Anal. 17(2), 253-271.

Tillitt, D. E., Ankley, G. T., Giesy, J. P., Ludwig, J. P., Kurita-Matsuba, H., Weseloh, D. V., Ross, P. S., Bishop, C. A., Sileo, L., Stromborg, K. L., Larson, J., and Kubiak, T. (1992). "Polychlorinated biphenyl residues and egg mortality in double-crested cormorants from the Great Lakes," Environ. Toxicol. Chem. 11, 1281-1288.

Underwood, A. J. (1989). “The analysis of stress in natural populations," Biol. J. Linnean Soc. 37, 51-78.

U.S. Army Corps of Engineers. "The Dredging Contaminants Bulletin Board System (BBS)," htttp://www.wes.army.mil/el/dredgbbs/index.html.

U.S. Army Engineer Division, Huntsville. (1995). "HTRW Risk Assessment: Proponent Sponsored Engineer Corps Training (PROSPECT)." Control \#222, Huntsville, AL.

U.S. Army Engineer Waterways Experiment Station. (1992). "Risk-based testing of dredged material for aquatic disposal evaluations," Environmental Effects of Dredging Program Technical Note EEDP-01-28, Vicksburg, MS.

U.S. Army Engineer Waterways Experiment Station. (1993). "The use of population modeling to interpret chronic sublethal sediment bioassays," Environmental Effects of Dredging Program Technical Note EEDP-04-19, Vicksburg, MS.

U.S. Army Engineer Waterways Experiment Station. (1995). "Trophic transfer and biomagnification potential of contaminants in aquatic ecosystems," Environmental Effects of Dredging Program Technical Note EEDP-01-33, Vicksburg, MS.

U.S. Environmental Protection Agency. (1992). "Guidance for data usability in risk assessment (Part A)," Publication No. PB92-9633556, Washington, DC. 
U.S. Environmental Protection Agency. (1993a). "Assessment and remediation of contaminated sediments (ARCS) program: Risk assessment and modeling overview document," EPA-905-R93-007, Great Lakes National Program Office, Chicago, IL.

U.S. Environmental Protection Agency. (1993b). "Technical basis for deriving sediment quality criteria for nonionic organic contaminants for the protection of benthic organisms by using equilibrium partitioning," EPA-822-R-93-011, Washington, DC.

U.S. Environmental Protection Agency. (1993c). "Wildlife exposure factors handbook," EPA-600-R-93-187a, Office of Research and Development, Washington, DC.

U.S. Environmental Protection Agency. (1994). "Workshop on the use of available data and methods for assessing the ecological risks of 2,3,7,8Tetrachlorodibenzo-p-dioxin to aquatic wildlife," EPA-630-R-94-002, Office of Research and Development, Washington, DC.

U.S. Environmental Protection Agency. (1996a). "Estimating contaminant losses from components of remediation alternatives for contaminated sediments," EPA-905-R96-001, Prepared for the Assessment and Remediation of Contaminated Sediments (ARCS) Program by the Great Lakes National Program Office, Chicago, IL.

U.S. Environmental Protection Agency. (1996b). "Proposed guidelines for ecological risk assessment," EPA-630-R-95-002B, Risk Assessment Forum, Washington, DC.

U.S. Environmental Protection Agency. (1996c). "Summary report for the Workshop on Monte Carlo Analysis," EPA-630-R-96-010, Office of Research and Development, Risk Assessment Forum, Washington, DC.

U.S. Environmental Protection Agency. (1997a). "Exposure factors handbook, Volumes I-III," EPA-600-P-95-002Fa-c, Office of Research and Development, Washington, DC.

U.S. Environmental Protection Agency. (1997b). "Guiding principles for Monte Carlo analysis," EPA-630-R-97-001, Risk Assessment Forum, Washington, DC.

U.S. Environmental Protection Agency. (1998a). "Guidelines for ecological risk assessment," EPA-630-R-95-002F, Risk Assessment Forum, Washington, DC.

U.S. Environmental Protection Agency. (1998b). Proceedings, National Sediment Bioaccumulation Conference. EPA-823-R-98-002. Office of Water, Washington, DC.

U.S. Environmental Protection Agency. (1998c). Integrated Risk Information System Database, http://www.epa.gov/iris. 
U.S. Environmental Protection Agency and U.S. Army Corps of Engineers. (1991). "Evaluation of dredged material proposed for ocean disposal: Testing Manual," EPA 503/8-91/001. http://www.epa.gov/OWOW/oceans/gbook.

U.S. Environmental Protection Agency and U.S. Army Corps of Engineers. (1992). "Evaluating environmental effects of dredged material management alternatives - a technical framework." EPA-842-B-92-008. http://www.epa.gov/OWOW/oceans/framework.

U.S. Environmental Protection Agency and U.S. Army Corps of Engineers. (1998). "Evaluation of dredged material proposed for discharge in waters of the U. S. - testing manual (The inland testing manual)." EPA 823-B-98-004. http://www.epa.gov/OST/pubs/ITM.html.

van Veld, P. V. (1997). "Modulation by signal transduction of multixenobiotic resistance in a population of tumor-bearing fundulus heteroclitus." Society of Environmental Toxicology and Chemistry, Eighteenth Annual Meeting, San Francisco, CA, 16-20 November 1997. Society of Environmental Toxicology and Chemistry, Pensacola, FL.

van Wezel, A. P., and Opperhuizen, A. (1995). "Narcosis due to environmental pollutants in aquatic organisms: Residue-based toxicity, mechanisms, and membrane burdens," Crit. Rev. Toxicol. 25, 255-279.

van Wezel, A. P., Dieuwke, A. M. de Vries, Kostense, S., Sijm, D. T. H. M., and Opperhuizen, A. (1995). "Intraspecies variation in lethal body burdens of narcotic compounds," Aquat. Toxicol. 33, 325-342.

Vose, D. (1996). Quantitative risk analysis: a guide to Monte Carlo simulation modeling. John Wiley \& Sons, New York. 


\section{REPORT DOCUMENTATION PAGE}

Public reporting burden for this collection of information is estimated to average 1 hour per response, including the time for reviewing instructions, searching existing data sources, gathering and maintaining the data needed, and completing and reviewing the collection of information. Send comments regarding this burden estimate or any other aspect of this collection of information, including suggestions for reducing this burden, to Washington Headquarters Services, Directorate for Information Operations and Reports, 1215 Jefferson Davis Highway, Suite 1204, Arlington, VA 22202-4302, and to the Office of Management and Budget, Paperwork Reduction Project (0704-0188), Washington, DC 20503.
1. AGENCY USE ONLY (Leave blank)
2. REPORT DATE
December 1998
3. REPORT TYPE AND DATES COVERED
Final report

4. TITLE AND SUBTITLE

Improving Dredged Material Management Decisions with Uncertainty Analysis

5. FUNDING NUMBERS

WU 33182

6. AUTHOR(S)

Donna J. Vorhees, Susan B. Kane Driscoll, Katherine von Stackelberg,

Todd S. Bridges

7. PERFORMING ORGANIZATION NAME(S) AND ADDRESS(ES)

Menzie-Cura and Associates, Inc.

One Courthouse Lane, Suite Two, Chelmsford, MA 01824;

U.S. Army Engineer Waterways Experiment Station

3909 Halls Ferry Road, Vicksburg, MS 39180-6199

9. SPONSORING/MONITORING AGENCY NAME(S) AND ADDRESS(ES)

U.S. Army Corps of Engineers

Washington, DC 20314-1000

8. PERFORMING ORGANIZATION REPORT NUMBER

Technical Report DOER-3

10. SPONSORING/MONITORING AGENCY REPORT NUMBER

\section{SUPPLEMENTARY NOTES}

Available from National Technical Information Service, 5285 Port Royal Road, Springfield, VA 22161.

12a. DISTRIBUTION/AVAILABILITY STATEMENT

12b. DISTRIBUTION CODE

Approved for public release; distribution is unlimited.

\section{ABSTRACT (Maximum 200 words)}

Uncertainty regarding the ecological and human health risks associated with dredged material disposal alternatives can lead to delayed, costly and unwise decisions. Uncertainty about the likelihood for unacceptable impacts can result from the lack of knowledge about critical elements or processes contributing to risk or natural variability in the same elements or processes. The objectives of this effort were to (a) describe in detail the uncertainty sources within the tiered evaluation process, (b) rank sources of uncertainty within the tiered evaluation process by degree of contribution, and (c) make preliminary recommendations for further refinement of the ranking. The most significant sources of uncertainty within the tiered evaluation process included identification of the contaminants of concern, the selection and use of reference sediments, trophic transfer of sediment-associated contaminants, the potential for chronic toxicity and the use of chronic sublethal bioassays, defining assessment and measurement end points during the conduct of an environmental risk assessment, the use of contaminant fate and transport models, tissue-based measures of toxicity, dose-response models for human receptors, and the toxicity of complex mixtures. Specific recommendations for the need for more extensive field validation for many of the components in the tiered evaluation process were made.

14. SUBJECT TERMS

Contaminated sediment

Dredged material
Risk assessment

Uncertainty
15. NUMBER OF PAGES

78

16. PRICE CODE

\section{SECURITY CLASSIFICATION OF REPORT \\ UNCLASSIFIED \\ 18. SECURITY CLASSIFICATION OF THIS PAGE UNCLASSIFIED}

19. SECURITY CLASSIFICATION OF ABSTRACT 